Universidade de São Paulo

Faculdade de Filosofia, Ciências e Letras de Ribeirão Preto Departamento de Química

Programa de Pós-Graduação em Química

\title{
Estudos in vitro enantiosseletivos do fungicida tebuconazol utilizando modelo humano: metabolismo, inibição enzimática e fenotipagem
}

\section{MAÍSA DANIELA HABENSCHUS}

Versão Resumida da Tese apresentada à Faculdade de Filosofia, Ciências e Letras de Ribeirão Preto da Universidade de São Paulo, como parte das exigências para a obtenção do título de Doutor em Ciências, Área: Química

RIBEIRÃO PRETO - SP

2021 


\title{
Estudos in vitro enantiosseletivos do fungicida tebuconazol utilizando modelo humano: metabolismo, inibição enzimática e fenotipagem
}

\author{
Versão Resumida
}

Versão Resumida da Tese apresentada à Faculdade de Filosofia, Ciências e Letras de Ribeirão Preto da Universidade de São Paulo, como parte das exigências para a obtenção do título de Doutor em Ciências

Área de Concentração: Química

Orientador: Prof. Dr. Anderson Rodrigo Moraes de Oliveira

RIBEIRÃO PRETO - SP 
Autorizo a reprodução e divulgação total ou parcial deste trabalho, por qualquer meio convencional ou eletrônico, para fins de estudo e pesquisa, desde que citada a fonte.

\section{FICHA CATALOGRÁFICA}

Habenschus, Maísa Daniela

Estudos in vitro enantiosseletivos do fungicida tebuconazol utilizando modelo humano: metabolismo, inibição enzimática e fenotipagem/ Maísa Daniela Habenschus; orientador, Anderson Rodrigo Moraes de Oliveira. - 2021 46 f. : il.

Tese (Doutorado em Ciências, Área Química) - Programa de Pós- Graduação em Química, Faculdade de Filosofia, Ciências e Letras de Ribeirão Preto, Universidade de São Paulo, Ribeirão Preto, 2021

Versão Resumida

1. Tebuconazol. 2. Praguicida. 3. Metabolismo in vitro. 4. Cinética enzimática. 5. Inibição enzimática. 6. Parâmetros toxicocinéticos. 7. Microssomas. 8. Enantiosseletivo. I. de Oliveira, Anderson Rodrigo Moraes, orient. II. Título. 
Nome: HABENSCHUS, Maísa Daniela

Título: Estudos in vitro enantiosseletivos do fungicida tebuconazol utilizando modelo humano: metabolismo, inibição enzimática e fenotipagem.

Versão Resumida da Tese apresentada à Faculdade de Filosofia Ciências e Letras de Ribeirão Preto da Universidade de São Paulo como parte das exigências para a obtenção do título de Doutor em Ciências

Área de Concentração: Química

Aprovada em:

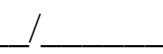

Banca Examinadora

Prof. Dr.

Instituição: Assinatura:

Prof. Dr.

Instituição: Assinatura:

Prof. Dr.

Instituição: Assinatura:

Prof. Dr.

Instituição: Assinatura:

Prof. Dr.

Instituição: Assinatura:

Prof. Dr.

Instituição: Assinatura: 


\section{AGRADECIMENTOS}

Segundo o escritor americano Jim Rohn, nós somos a média das cinco pessoas com quem passamos mais tempo. Se isso for verdade, não tenho do que reclamar, pois nesses anos de Doutorado sempre estive cercada de excelentes pessoas e profissionais. A sensação de dever cumprido e gratidão que sinto hoje eu devo dividir com vocês.

Primeiramente, agradeço aos meus pais, Luíz Carlos e Maria Helena, que são meu alicerce, е ао теи irmão Lucas. Obrigada por sempre me apoiarem e pelos esforços que fizeram para que eu chagasse até aqui, muitas vezes abrindo mão de sonhos próprios para que eu realizasse os meus.

Ao meu orientador, Prof. Dr. Anderson. Obrigada pela parceria, compreensão, apoio e pelos ensinamentos que vão além do mundo acadêmico.

À Raíssa Ferrari, por estar presente na maioria das minhas vitórias. Obrigada pelo companheirismo, por ser minha confidente e por sempre me ensinar a ver o lado positivo das coisas e a ser uma pessoa melhor.

A todos os amigos que passaram pelo LABMETs durante esses anos, em especial ao Daniel, Nayara, Franciele e Ícaro. Aprendi muito com vocês. Obrigada por transformarem dias difíceis em dias mais leves. Com vocês cresci pessoalmente e profissionalmente.

Aos meus companheiros de SABESP, que sempre me incentivaram a concluir essa importante etapa da minha carreira.

Ao professor Luís Gustavo Dias e sua aluna Viviani Nardini, pela colaboração nos cálculos de determinação das configurações absolutas.

Ao professor Fernando Barbosa Júnior, pela disponibilização de seu laboratório e do equipamento de CLAE-EM/EM, e em especial ao então seu aluno de pós-doutorado, Bruno Alves Rocha, pelo auxílio durante as análises. Muito Obrigada!

Ao professor Norberto Peporine Lopes e seu aluno de pós-doutorado, Rodrigo Moreira, pela colaboração, disponibilização do equipamento de CLAE-EM/EM e auxílio nas análises dos ensaios de inibição enzimática.

Ao Programa de Pós-Graduação em Química da Faculdade de Filosofia Ciências e Letras de Ribeirão Preto, bem como a todos os professores, técnicos e funcionários, que de maneira direta ou indireta fizeram parte desses anos de Doutorado. 
Às Agências de Fomento, Fundação de Pesquisa do Estado de São Paulo (FAPESP), ao Conselho Nacional de Desenvolvimento Científico e Pesquisa (CNPQ) pelo auxílio financeiro.

À Coordenação de Aperfeiçoamento de Pessoal de Nível Superior (CAPES) pela bolsa concedida (código de financiamento 001). 


\section{RESUMO}

HABENSCHUS, M. D. Estudos in vitro enantiosseletivos do fungicida tebuconazol utilizando modelo humano: metabolismo, inibição enzimática e fenotipagem. 2021. $46 \mathrm{f}$. Tese (Doutorado em Ciências, Área Química) - Faculdade de Filosofia, Ciências e Letras de Ribeirão Preto, Universidade de São Paulo, Ribeirão Preto, 2021.

As pessoas estão constantemente expostas a resíduos de praguicidas, seja de maneira indireta, através do consumo de água e alimentos contaminados, seja de maneira direta, como a exposição de trabalhadores rurais que aplicam praguicidas nas lavouras. Além da preocupação com a exposição do homem a esses compostos, outra questão importante diz repeito aos riscos que os praguicidas quirais representam para a saúde humana. Enantiômeros de praguicidas quirais podem diferir quanto a absorção, distribuição, metabolismo e excreção, além da toxicidade e bioacumulação em organismos não-alvo. O tebuconazol (TEB), composto em estudo neste trabalho, é um praguicida quiral da classe dos triazóis. Ele é empregado na forma de mistura racêmica para o controle do crescimento de fungos e como conservante de madeira. Estudos enantiosseletivos do TEB indicam que seus enantiômeros apresentam diferenças de atividade biológica e toxicidade para organismos aquáticos não-alvo e, portanto, o metabolismo e a toxicidade para o homem também podem ser enantiosseletivos e devem ser estudados. Baseando-se nisso, o presente trabalho propôs avaliar, de maneira enantiosseletiva, o metabolismo in vitro de fase I do TEB utilizando modelo humano, bem como o potencial inibitório deste composto frente as principais enzimas do citocromo P450 (CYP450) a fim de verificar o risco de possíveis interações praguicida-fármacos. Para isso, um método analítico enantiosseletivo por cromatografia líquida de alta eficiência foi desenvolvido e validado, permitindo a análise simultânea dos enantiômeros do TEB e do seu principal metabólito, 1hidroxitebuconazol (TEBOH). Importantes parâmetros metabólicos in vitro foram obtidos e extrapolações in vitro-in vivo foram realizadas para calcular alguns parâmetros toxicocinéticos. Os resultados mostraram que as enzimas do CYP450 presentes nos microssomas hepáticos de humanos são capazes de metabolizar o TEB em TEBOH e perfis cinéticos de Michaelis-Menten e perfis bifásicos atípicos foram observados. Ademais, pode ocorrer metabolismo preferencial do $S$-(+)-TEB comparado ao rac-TEB e $R$-(-)-TEB, com formação preferêncial do $S$-(+)TEBOH. Os estudos de fenotipagem revelaram que múltiplas isoformas do CYP450 estão envolvidas no metabolismo do TEB em TEBOH, com destaque para a CYP3A4 e CYP2C9. Os estudos de inibição enzimática mostraram que o TEB pode inibir as enzimas CYP3A4/5, CYP2C9, CYP2C19 e CYP2D6. Os mecanismos e constantes de inibição foram determinados apenas para o rac-TEB, que mostrou ser um inibidor misto forte da CYP3A4/5 e CYP2C9 e um inibidor competitivo moderado e forte da CYP2D6 e CYP2C19, respectivamente. Além disso, os valores das constantes de inibição indicaram que o risco de interações rac-TEBfármacos não pode ser ignorado, principalmente interações com fármacos metabolizados majoritariamente pela CYP3A4/5, CYP2C9 e CYP2C19. Dessa forma, esses resultados juntos contribuem para a avaliação do risco de exposição humana ao praguicida quiral TEB e esse risco não deve ser negligenciado.

Palavras- chave: Tebuconazol. Praguicida. Metabolismo in vitro. Cinética enzimática. Inibição enzimática. Parâmetros toxicocinéticos. Microssomas. Enantiosseletivo. 


\section{ABSTRACT}

HABENSCHUS, M. D. In vitro enantioselective studies of the fungicide tebuconazole using human model: metabolism, enzyme inhibition and phenotyping. 2021. 46 p. Tese (Doutorado) - Faculdade de Filosofia, Ciências e Letras de Ribeirão Preto, Universidade de São Paulo, Ribeirão Preto, 2021.

People are constantly exposed to pesticide residues, either indirectly, through the consumption of contaminated water and food, or directly, such as the exposure of agricultural workers who apply pesticides to the crops. In addition to the concern with human's exposure to these compounds, another important issue is the risk that chiral pesticides pose to human health. Enantiomers of chiral pesticides may have different absorption, distribution, metabolism and excretion in human body, besides toxicity and bioaccumulation in non-target organisms. Tebuconazole (TEB), the compound in study in this work, is a chiral triazole pesticide worldwide used as racemic mixture to control fungal plant pathogens and as wood preservative. Enantioselective studies with TEB indicate that its enantiomers have different biological activities and toxicity to non-target organisms, so the metabolism and toxicity of TEB in human body may also be enantioselective and should be studied. Therefore, the present work proposed to evaluate, enantioselectively, the in vitro phase I metabolism of TEB by using human model and also evaluate the inhibitory potential of TEB over the main cytochrome P450 (CYP450) enzymes in order to verify the risk of pesticide-drug interactions. An enantioselective analytical method using high performance liquid chromatography was developed and validated to simultaneously analyze the enantiomers of TEB and its main metabolite, 1hydroxytebuconazole (TEBOH). Important in vitro metabolic parameters were obtained, and in vitro-in vivo extrapolations were performed to calculate some toxicokinetic parameters. The results showed that the CYP450 enzymes present in the human liver microsomes are able to metabolize TEB into TEBOH and Michaelis-Menten kinetic profiles and also atypical biphasic kinetic profiles were observed. Furthermore, preferential metabolism of $S$-(+)-TEB over racTEB and $R-(-)$-TEB may occur, with preferential production of $S-(+)-T E B O H$. Phenotyping reaction studies have shown that multiple CYP450 isoforms catalyzed TEB metabolism when TEBOH enantiomers were produced, mainly CYP3A4 and CYP2C9. The enzyme inhibition studies showed that the TEB can inhibit CYP3A4/5, CYP2C9, CYP2C19 and CYP2D6. The inhibition mechanisms and constants were determined only for rac-TEB, which was a strong mixed-type inhibitor of CYP3A4/5 and CYP2C9 and a moderate and strong competitive inhibitor of CYP2D6 and CYP2C19, respectively. In addition, the values of inhibition constants suggested the risk of rac-TEB-drug interactions cannot be ignored, especially with drugs metabolized mainly by CYP3A4/5, CYP2C9 and CYP2C19. Thus, the results together contribute to the risk assessment of human exposure to the chiral pesticide TEB, and the risk should not be neglected.

Keywords: Tebuconazole. Pesticide. In vitro metabolism. Enzyme kinetics. Enzyme inhibition. Toxicokinetic parameters. Microsome. Enantioselective. 


\section{LISTA DE FIGURAS}

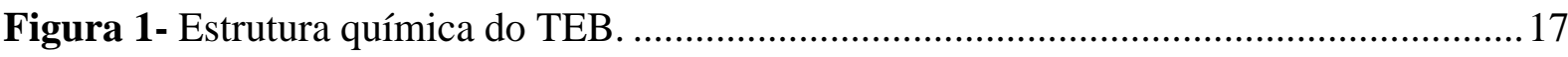

Figura 2- Estrutura química dos principais metabólitos do TEB em diferentes espécies. ...... 20

Figura 3- Representação simplificada das etapas que compõem a toxicocinética de um

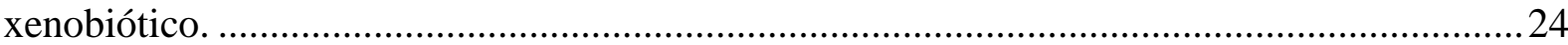

Figura 4- Gráficos de velocidade inicial da reação $\left(\mathrm{v}_{0}\right)$ vs a concentração de substrato ([S]) representando o perfil cinético de A) Michaelis-Menten e C) bifásico. B) e D) representam os gráficos de Eadie-Hofstee para uma cinética de Michaelis-Menten e para uma cinética bifásica,

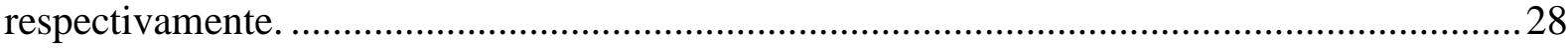




\section{LISTA DE TABELAS}

Tabela 1- Reações específicas catalisadas pelas isoformas do CYP450 que podem ser monitoradas nos estudos in vitro de inibição enzimática e os respectivos metabólitos formados. 


\section{LISTA DE ABREVIATURAS E SIGLAS}

[S], concentração de substrato

ADME, absorção, distribuição, metabolismo e excreção

ANVISA, Agência Nacional de Vigilância Sanitária

CLAE, cromatografia líquida de alta eficiência

CLAE-DAD, cromatografia liquida de alta eficiência acoplada ao detector de arranjo de diodos

CLAE-EM, cromatografia líquida de alta eficiência acoplada à espectrometria de massas

CLAE-EM/EM, cromatografia líquida de alta eficiência acoplada à espectrometria de massas sequencial

$\mathrm{CL}_{\mathrm{H}}$, clearance hepático, obtido por extrapolação

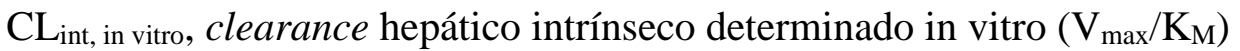

$\mathrm{CL}_{\text {int, in vivo, }}$ clearance hepático intrínseco in vivo, obtido por extrapolação

CYP450, citocromo P450

CYP51, enzima lanosterol 14- $\alpha$-demetilase

$\mathrm{DAD}$, detector de arranjo de diodos

E, enzima livre

$\mathrm{E}_{\mathrm{H}}$, taxa de extração hepática, obtida por extrapolação

EI, complexo enzima- inibidor

EM, espectrometria de massas

ES, complexo enzima-substrato

ESI, complexo enzima-substrato-inibidor

FEQ, fases estacionárias quirais

HLM, human liver microsomes, microssomas hepáticos de humanos

$\mathrm{IC}_{50}$, concentração do composto que inibe em $50 \%$ a atividade de uma determinada enzima

$\mathrm{K}_{\mathrm{i}}$, constante de inibição reversível, constante de dissociação do complexo EI

$\mathrm{K}_{\mathrm{M}}$, constante de Michaelis-Menten

$\mathrm{NADPH}$, nicotinamida adenina dinucleotídeo fosfato reduzido

ONU, United Nation, Organização das Nações Unidas

$\mathrm{P}$, produto

Rac-TEB, mistura racêmica do tebuconazol

rCYP450, isoformas recombinantes do CYP450

Rs, resolução 
$R$-TEB, enantiômero $R$ - do tebuconazol

S, substrato

SQ, seletor quiral

$S$-TEB, enantiômero $S$ - do tebuconazol

$\mathrm{T}_{1 / 2}$, meia vida

TEB, tebuconazol

TEBOH, 1-hidroxitebuconazol

$t_{R}$, tempo de retenção

USEPA, United States Environmental Protection Agency, Agência de Proteção Ambiental dos

Estados Unidos

v0, velocidade inicial da reação

$\mathrm{V}_{\max }$, velocidade máxima da reação

WHO, World Health Organitazion, Organização Mundial da Saúde

$\alpha \mathrm{K}_{\mathrm{i}}$, constante de dissociação do complexo ESI para a inibição do tipo mista 


\section{SUMÁRIO}

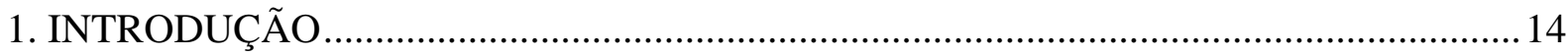

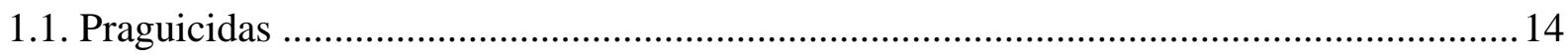

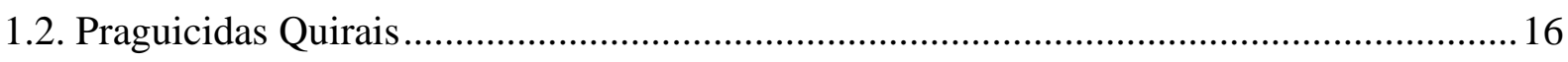

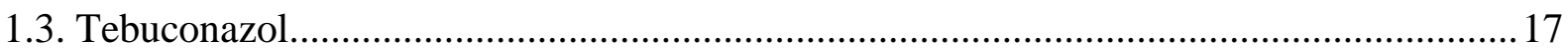

1.4. Separação e análise enantiosseletiva do tebuconazol e seu metabólito, 1-hidroxitebuconazol .

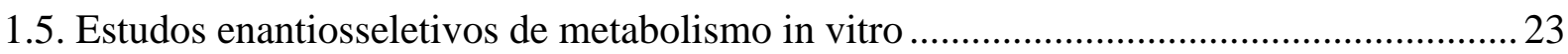

1.5.1. Cinética enzimática e extrapolações in vitro- in vivo ................................................... 26

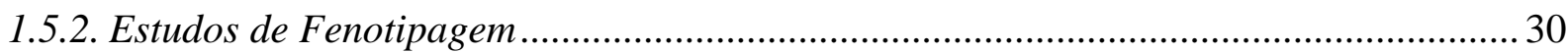

1.6. Estudos enantiosseletivos de inibição enzimática: interação praguicida- fármaco ........... 32

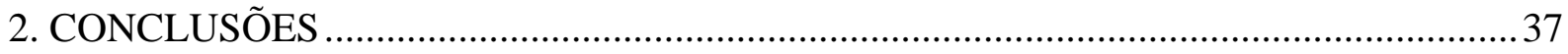

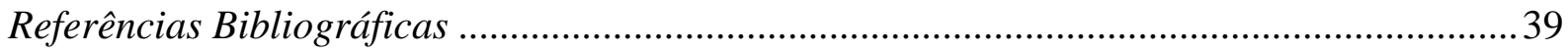




\section{INTRODUÇÃO}

\subsection{Praguicidas}

Segundo a Organização Mundial da Saúde (WHO, World Health Organization) praguicidas (pesticides) são compostos químicos usados para matar pragas, incluindo insetos, roedores, fungos e plantas indesejáveis (ervas daninhas) (WHO, 2018). Já a Agência de Proteção Ambiental dos Estados Unidos (USEPA, Environmental Protection Agency) classifica praguicidas como substâncias, ou misturas de substâncias, utilizadas para prevenir, repelir, mitigar ou destruir alguma praga. Tais substâncias também podem ser utilizadas como agentes reguladores de crescimento, desfolhantes, dessecantes, ou então como estabilizadores de nitrogênio (USEPA, 2007).

No Brasil, os praguicidas têm diversas denominações, tais como agrotóxicos, agroquímicos, pesticidas, defensivos fitossanitários ou agrícolas, dentre outras. Eles são definidos como produtos e agentes de processos físicos, químicos ou biológicos, destinados ao uso nos setores de produção, no armazenamento e beneficiamento de produtos agrícolas, nas pastagens, na proteção de florestas, nativas ou plantadas, e de outros ecossistemas e ambientes urbanos, hídricos e industriais. Além disso, segundo a definição brasileira, a finalidade dos praguicidas é alterar a composição da flora ou da fauna a fim de preservá-las da ação danosa de seres vivos considerados nocivos e também atuar como agentes desfolhantes, dessecantes, estimuladores e inibidores de crescimento (MINISTÉRIO DO MEIO AMBIENTE, 2018).

Os praguicidas são classificados com base no organismo-alvo que combatem. Os fungicidas são usados no controle de fungos, inseticidas no controle de insetos, bactericidas no controle de bactérias, nematicidas no controle de nematoides, dentre outros, e, do ponto de vista da agricultura, o uso desses compostos é visto como algo necessário e vantajoso. Um dos benefícios, por exemplo, é a redução da população de vetores responsáveis por propagar doenças, fazendo com que haja um controle das pragas e uma diminuição dos danos provocados nas plantações. Isso acarreta, consequentemente, uma produção mais eficiente de alimentos em uma menor área de cultivo e tais alimentos tendem a durar mais tempo na prateleira (POPP; PETÖ; NAGY, 2013).

Esses benefícios são muito importantes quando levamos em consideração o aumento da população e a necessidade de se produzir cada vez mais alimentos para abastecê-la. De acordo com levantamentos realizados pela Organização das Nações Unidas (ONU, United Nations), a 
população mundial está projetada para ser de 9 bilhões de pessoas no ano de 2050 e de 11,2 bilhões em 2100 (UN, 2017). Assim, para acompanhar esse crescimento, a produção de alimentos tem que necessariamente aumentar. Em contrapartida, a existência de novas áreas para plantio é limitada, sendo necessário então um aumento de produção das lavouras já existentes, e uma das maneiras de se conseguir isso é através de um maior consumo mundial de praguicidas (BONNER; ALAVANJA, 2017; POPP; PETÖ; NAGY, 2013).

Atualmente, o Brasil se destaca como um dos maiores consumidores mundiais desses compostos. Dados revelam que a venda de praguicidas no país movimenta em torno de 10 bilhões de dólares por ano, o que representa cerca de $20 \%$ do mercado global (VASCONCELOS, 2018). Além disso, em 2017 os produtores brasileiros aplicaram cerca de 540 mil toneladas de praguicidas nas lavouras, o que corresponde a um aumento de $50 \%$ quando comparado ao ano de 2010 (VASCONCELOS, 2018). Esse elevado consumo tornou o Brasil um dos maiores produtores e exportadores de importantes culturas agrícolas, principalmente de grãos, como a soja. Porém, o uso crescente desses compostos tem levantado preocupações a respeito dos danos que podem ser causados ao meio ambiente e os efeitos que podem causar na saúde humana (BONNER; ALAVANJA, 2017).

Já é conhecido que muitos praguicidas são persistentes no meio ambiente, podem acumular em seres vivos, ser tóxicos para organismos não alvo, além de serem transportados a longo alcance. Isso faz com que possam contaminar o solo, o ar, a água e os alimentos. Dessa forma, as pessoas podem ser expostas a resíduos de praguicidas seja através da alimentação ou respiração, chamado de exposição indireta, ou então através de uma exposição direta, que como o nome já diz, ocorre quando a pessoa tem contato direto com o praguicida, como por exemplo, trabalhadores rurais que aplicam esses produtos e que não utilizam ou fazem o uso incorreto dos equipamentos de proteção individual (EPIs), o que é uma realidade muito presente no Brasil (CARGNIN; ECHER; SILVA, 2017; DE LUCCA et al., 2012).

Um levantamento feito pela Agência Nacional de Vigilância Sanitária (ANVISA) entre os anos de 2017 e 2018 apontou que, do total das amostras de alimentos analisadas naquele período no Brasil, 51\% delas apresentavam resíduos de praguicidas. Desses 51\%, 28\% das amostras apresentaram concentrações abaixo do limite máximo de resíduos permitidos (LMR) enquanto que $23 \%$ eram consideradas amostras insatisfatórias, ou seja, a concentração do praguicida estava acima do LMR, ou havia a presença de pelo menos um praguicida de uso proibido para aquele tipo de lavoura, ou então havia a presença de praguicidas cujo uso já havia sido banido no Brasil (ANVISA, 2019). 
Dessa forma, fica evidente que estamos expostos a esses compostos e por isso não é difícil encontrar na literatura trabalhos que mostrem a presença de resíduos de praguicidas, ou de metabólitos de praguicidas, em amostras biológicas humanas, como por exemplo amostras de cabelo, sangue e urina (CARVALHO et al., 2018; MERCADANTE et al., 2014; RUDGE et al., 2012; TSATSAKIS et al., 2010).

Como o modo de ação dos praguicidas não é, muitas vezes, espécie-específico, ou seja, os danos não são causados apenas aos organismos-alvo, a exposição a esses compostos pode provocar, a curto prazo, efeitos tóxicos agudos nas pessoas, como irritação dos olhos e da pele, dores de cabeça e enjoo. Ademais, caso a exposição seja constante e dependendo da dose e da toxicidade do mesmo, podem surgir, ao longo dos anos, problemas crônicos de saúde, como doença de Alzheimer, câncer, disfunções neurológicas e hormonais, asma, alergias, dentre outros (KIM; KABIR; JAHAN, 2017).

Portanto, há uma preocupação recorrente da comunidade científica com o crescente aumento no uso de praguicidas e a consequente exposição do homem a esses compostos.

\subsection{Praguicidas Quirais}

Outra questão importante envolvendo praguicidas diz respeito aos riscos que o uso de praguicidas quirais representam para a saúde humana e para o meio ambiente (DE ALBUQUERQUE et al., 2018).

Moléculas quirais são moléculas que não tem um plano interno de simetria e que apresentam elementos de quiralidade, tais como eixos, planos ou o mais comum deles, os centros de quiralidade (CHANKVETADZE, 2017). Cada centro de quiralidade nessas moléculas indica que existe um par de compostos com a mesma fórmula molecular, as mesmas ligações entre os átomos e que se distinguem apenas pela disposição espacial dos substituintes, sendo suas estruturas imagens especulares uma da outra, não sobreponíveis, também chamados de enantiômeros (CHANKVETADZE, 2017).

Os enantiômeros têm características peculiares que fazem com que eles sejam objeto de estudos. Em um ambiente aquiral, os enantiômeros de um mesmo composto têm propriedade físico-químicas idênticas, como ponto de fusão, ponto de ebulição e solubilidade, podendo ser distinguidos apenas pelas diferenças de atividade óptica: um enantiômero desvia o plano da luz polarizada para a esquerda, chamado de levogiro ( $l$ - ou - ), enquanto que o outro desvia o plano da luz polarizada para a direita, chamado de dextrogiro $(d-$ ou + ) (MCMURRY, 2012). Porém, 
em um meio contendo moléculas quirais, os enantiômeros podem se comportar como dois compostos distintos (DE ALBUQUERQUE et al., 2018).

Como os organismos vivos têm moléculas quirais em suas estruturas, qualquer interação que envolva uma proteína, um transportador ou uma enzima, pode ocorrer de maneira diferente para os enantiômeros, ou seja, ser enantiosseletiva (DEFRA, 2002). Dessa forma, enantiômeros de praguicidas quirais podem apresentar diferenças de atividade biológica, toxicidade, bioacumulação e metabolismo, por exemplo.

Atualmente, cerca de $30 \%$ dos praguicidas registrados são moléculas quirais (JESCHKE, 2018). Por questões econômicas, a maioria dos praguicidas quirais é comercializado na forma de mistura racêmica, sendo apenas $7 \%$ deles comercializados como enantiômeros isolados ou misturas enriquecidas de um dos enantiômeros. Devido a isso, autoridades têm chamado a atenção para a necessidade de um maior entendimento do comportamento e dos efeitos desses enantiômeros em organismos não-alvo. Portanto, em estudos de avaliação de risco de praguicidas quirais, os enantiômeros precisam ser tratados como compostos diferentes (BURA et al., 2019).

\subsection{Tebuconazol}

O tebuconazol (TEB), (RS)-1-p-clorofenil-4,4-dimetil-3(1H-1,2,4-triazol-1-ilmetil) pentan-3-ol (Figura 1), composto alvo desse trabalho, é um fungicida sistêmico da classe dos triazóis mundialmente comercializado e utilizado em culturas de cereais, frutas, vegetais, dentre outras, e também como conservante de madeira. Sua função consiste em inibir a enzima lanosterol 14- $\alpha$-demetilase (CYP51), que é uma enzima da família do complexo do citocromo P450 (CYP450) responsável por regular a biossíntese de ergosterol. O ergosterol está presente na membrana celular dos fungos e atua mantendo a integridade desta (CHEN et al., 2018).

Figura 1- Estrutura química do TEB.

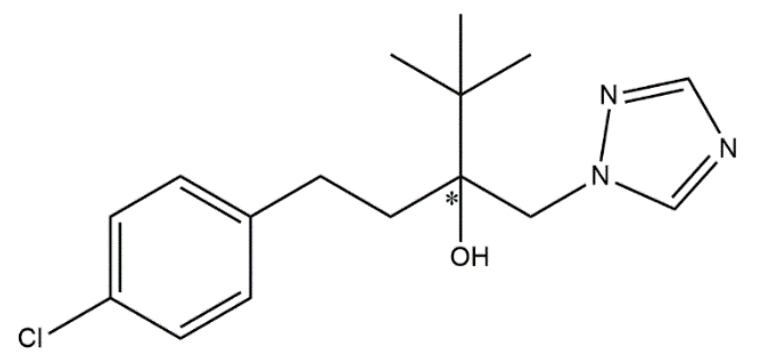

*Centro quiral. Fonte: Autoria própria. 
De acordo com ensaios toxicológicos, ainda que o emprego do TEB na agricultura seja considerado seguro por autoridades regulatórias (ESFA, 2014a), ele é classificado pela USEPA como um possível carcinogênico humano (classificação C, USEPA, 1996). Além disso, estudos apontam que, dependendo da concentração, o TEB pode causar má formação em fetos de animais (MA et al., 2021) e tem a capacidade de interferir nas funções celulares de trofoblastos da placenta humana, o que indica que seu efeito na gestação e também na formação de fetos humanos deve ser melhor avaliado (ZHOU et al., 2016). O TEB também pode agir como desregulador endócrino em diferentes espécies (LI et al., 2019; LV et al., 2017), por exemplo, em ratos, produzindo efeitos antiandrogênicos em adultos e reduzindo o nível de testosterona e o número de espermatozoides (YANG et al., 2018). Efeitos indesejáveis no fígado também já foram observados, como o aumento do peso hepático em ratos e hipertrofia centrolobular em camundongos (ESFA, 2014a; SCHMIDT et al., 2016).

Por ser muito estável a degradação no solo, o TEB é classificado como um praguicida de moderada a alta persistência, sendo que a sua meia-vida ( $\left.\mathrm{t}_{1 / 2}\right)$ varia de cerca de 40 até 600 dias (BADAWI et al., 2016; BENDING; RODRÍGUEZ-CRUZ; LINCOLN, 2007; ESFA, 2014a; STRICKLAND; POTTER; JOO, 2004). Apesar de ter um relativo baixo potencial de mobilidade, principalmente em solos com muita matéria orgânica (UN, 1994), monitoramentos mostram que os níveis de TEB encontrados em sedimentos, águas superficiais, subterrâneas e água tratada vêm aumentando ao longo do anos (BAUGROS et al., 2008; DE SOUZA et al., 2020; HERRERO-HERNÁNDEZ et al., 2013; SÁNCHEZ-GONZÁLEZ et al., 2013).

Trabalhos científicos também apontam seu potencial de acumulação em rãs selvagens (POULSEN et al., 2015) e peixes (CLASEN et al., 2018; EUROPEAN CHEMICAL AGENCY, 2013), e a presença de resíduos em alimentos (FREEMAN et al., 2016; NOUGADÈRE et al., 2020; SAITTA et al., 2017). No Brasil, o TEB foi detectado em 12\% das amostras de alimentos monitoradas pela ANVISA entre os anos de 2017 e 2018, o que equivale a 570 amostras. Em amostras de goiaba, pimentão e batata-doce, por exemplo, chegou a ser encontrado até mesmo acima do LMR (0,2 $\mathrm{mg} \mathrm{kg}^{-1}$ ) (ANVISA, 2019), o que eleva o risco de exposição indireta do homem a esse composto.

Trabalhadores que aplicam esse praguicida também sofrem exposição laboral direta, e muitos, por não utilizarem corretamente os EPIs, estão sujeitos a se exporem, principalmente, por absorção dérmica, com concentrações de TEB acima do limite aceitável (ESFA, 2014a; FUSTINONI et al., 2014; MERCADANTE et al., 2014). Além disso, há indícios de que o TEB 
absorvido por via dérmica pode acumular no tecido adiposo (JÓNSDÓTTIR et al., 2016). Dessa forma, todas as evidências científicas mencionadas anteriormente sugerem que o uso desse praguicida pode apresentar riscos para a saúde humana e, portanto, estudos acerca do seu potencial tóxico em modelos humanos tornam-se relevantes.

A degradação, biotransformação e/ou metabolismo do TEB já foi estudada em diferentes plantas, como trigo, e animais, como ratos, coelhos, cabras e galinhas. Os principais metabólitos formados foram reportados e estão exemplificados na Figura 2. Em plantas, a alanina triazol merece destaque. Já em animais, os principais metabólitos são os produtos de reações de hidroxilação e carboxilação da fração terc-butil, seguido de reações de conjugação. O 1-hidroxitebuconazol (TEBOH) e o tebuconazol-ácido carboxílico, além de conjugados glicuronídeos e sulfatados, foram os compostos encontrados em maiores concentrações.

A presença desses metabólitos em amostras de urina de trabalhadores rurais que fazem a aplicação do TEB em vinhedos, conforme reportado por FUSTINONI et al., 2014 e MERCADANTE et al., 2014, é uma outra evidência que indica a contaminação humana por esse composto, nesse caso, devido a uma exposição direta. Em tal estudo, o TEBOH foi o metabólito encontrado em maior concentração $\left(0,025-1,198 \mu \mathrm{mol} \mathrm{L} \mathrm{L}^{-1}\right)$. 
Figura 2- Estrutura química dos principais metabólitos do TEB em diferentes espécies.

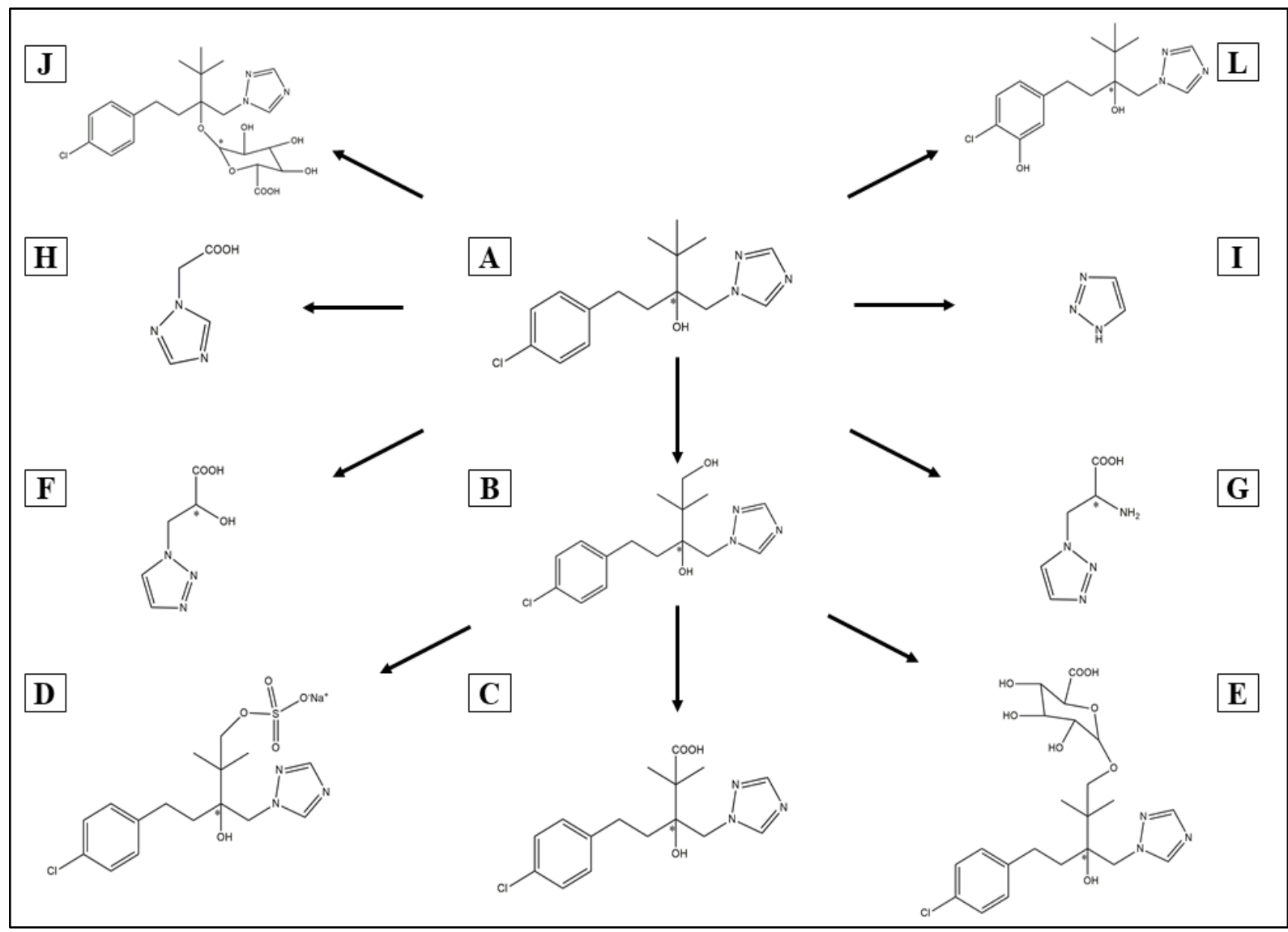

A) Tebuconazol, B) 1-hidroxitebuconazol (TEBOH), C) tebuconazol-ácido carboxílico, D) 1- hidroxisulfato de tebuconazol, E) 1-hidroxitebuconazol glicuronídeo, F) ácido triazol lático, G) alanina triazol, H) ácido triazol acético, I) 1,2,4-triazol, J) tebuconazol glicuronídeo, L) m-hidroxitebuconazol. *Centro quiral. Fonte: Autoria própria.

Conforme é possível observar na Figura 1 e Figura 2, o TEB é um composto quiral, com um centro de assimetria no átomo de carbono da porção álcool, sendo constituído por um par de enantiômeros, o $R$-tebuconazol ( $R$-TEB) e o $S$-tebuconazol ( $S$-TEB). Apesar de demonstrar enantiosseletividade em diferentes processos, o TEB ainda é comercializado e utilizado na forma de mistura racêmica ( $r a c$-tebuconazol, $r a c$-TEB).

Por exemplo, já se sabe que a sua atividade fungicida é enantiosseletiva, com o $R$-TEB sendo mais ativo que o $S$-TEB (CUI et al., 2018), enquanto que o $S$-TEB tem maior capacidade de regular o crescimento de plantas (STEHMANN; DE WAARD, 1995). O $R$-TEB também já demonstrou ser mais tóxico para organismos aquáticos não-alvo (Danio rerio, Scenedesmus obliquus, Daphnia magna) (LI et al., 2015), ser degradado mais lentamente do que o $S$-TEB em solos em condições aeróbias e anaeróbias (LI et al., 2015) e também bioacumular preferencialmente em peixes-zebra (Danio rerio) (LIU et al., 2016). 
Com relação ao metabolismo, a degradação enantiosseletiva do TEB já foi avaliada em diferentes espécies de animais. Em coelhos, por exemplo, a degradação foi investigada através da injeção intravenosa do rac-TEB e a quantificação das concentrações dos enantiômeros presentes no plasma indicou uma disposição enantiosseletiva, com o $S$-TEB sendo degradado mais rapidamente do que o $R$-TEB (ZHU et al., 2007). Em ratos, por sua vez, o metabolismo in vitro enantiosseletivo foi investigado utilizando microssomas hepáticos. Nesse estudo, após a incubação do rac-TEB, foi observado que a degradação do $S$-TEB foi mais rápida do que a do $R$-TEB, porém quando os enantiômeros foram avaliados separadamente não foi observada diferença significativa. Os parâmetros cinéticos também foram determinados empregando ambos os enantiômeros isolados, individualmente, e os valores da constante de MichaelisMenten $\left(\mathrm{K}_{\mathrm{M}}\right)$ foram semelhantes, enquanto que a velocidade máxima da reação $\left(\mathrm{V}_{\max }\right)$ foi ligeiramente maior para o enantiômero $R$-TEB (SHEN et al., 2012).

Nesse contexto, considerando o amplo emprego do TEB mundialmente, a crescente exposição do homem a esse composto e as distintas propriedades de seus enantiômeros dependendo da espécie ao qual são expostos, entender seu metabolismo e avaliar a sua capacidade de inibir as enzimas do CYP450, e se esses processos ocorrem ou não de maneira enantiosseletiva, são etapas essenciais no processo de avaliação de risco desse praguicida para o homem.

\subsection{Separação e análise enantiosseletiva do tebuconazol e seu metabólito, 1- hidroxitebuconazol}

Nos estudos de metabolismo in vitro enantiosseletivo de praguicidas quirais é necessário, na grande maioria das vezes, uma etapa inicial de desenvolvimento de métodos analíticos que permitam a separação dos enantiômeros do praguicida para monitorar o seu decaimento, ou então a separação dos enantiômeros dos metabólitos formados durante a reação, caso eles também sejam moléculas quirais (DE ALBUQUERQUE et al., 2018).

Para isso podem ser empregadas diferentes técnicas analíticas de separação, tais como a cromatografia gasosa, a cromatografia em fluído supercrítico, as técnicas de eletromigração, como por exemplo a eletroforese capilar, e a cromatografia líquida de alta eficiência (CLAE), todas acopladas aos mais diversos tipos de detectores (CARRÃO et al., 2020)

A CLAE acoplada ao detector de arranjos de diodos (CLAE-DAD) é a técnica mais difundida para esses estudos (DE ALBUQUERQUE et al., 2018), contudo aplicações 
empregando a cromatografia líquida de alta eficiência acoplada à espectrometria de massas (CLAE-EM) e à espectrometria de massas sequencial (CLAE-EM/EM) têm ganhado destaque, principalmente devido à alta seletividade e detectabilidade dos métodos desenvolvidos por essas técnicas (DE ALBUQUERQUE et al., 2018).

As análises quirais por cromatografia líquida podem ser feitas utilizando o método indireto, em que é necessário uma etapa prévia de derivatização do analito com um reagente quiral enantiomericamente puro para posterior análise dos diastereoisômeros formados empregando uma coluna aquiral, ou utilizando o método direto, em que são empregadas, na maioria das vezes, colunas com fases estacionárias ligadas aos mais diversos tipos seletores quirais (SQ), denominadas fases estacionárias quirais (FEQs) (LÄMMERHOFER, 2010). As FEQs são, na sua maioria, colunas a base de suportes de sílica funcionalizados com um SQ que é covalentemente ligado ou fisicamente adsorvido a estes (LÄMMERHOFER, 2010).

Existem diversos tipos de SQ, como por exemplo amilose, celulose, ciclodextrinas e antibióticos macrocíclicos. Os SQ mais empregados são aqueles derivados de polissacarídeos como a amilose e a celulose, sendo que FEQs derivadas de amilose e celulose com grupamentos fenilcarbamatos são as mais empregadas em estudos de metabolismo de praguicidas quirais (DE ALBUQUERQUE et al., 2018).

A resolução (Rs) entre os enantiômeros de um praguicida acontece, inicialmente, através do reconhecimento quiral. O reconhecimento quiral se dá pela formação de complexos diastereoisoméricos transientes entre o SQ e os enantiômeros. As constantes de formação de cada um desses complexos tendem a ser diferentes, o que resulta em tempos de retenção $\left(t_{R}\right)$ distintos para o par de enantiômeros e, por fim, a separação destes (LÄMMERHOFER, 2010).

Dentre os tipos de interações intermoleculares que contribuem para a formação dos complexos diastereoisoméricos transientes podem ser citadas as interações eletrostáticas, ligações de hidrogênio, interações $\pi$ - $\pi$, íon-dipolo, dipolo-dipolo, dipolo induzido-dipolo e dipolo induzido-dipolo induzido (DE CAMPOS LOURENÇO; CASSIANO; CASS, 2010), sendo que essas interações podem ser atrativas ou repulsivas.

Além disso, a fase móvel também influencia nas interações intermoleculares e na força com que elas ocorrem. Quando é utilizado, na fase móvel, um solvente de alta polaridade em maior quantidade, como no modo reverso de eluição, as interações eletrostáticas entre o analito e a fase estacionária perdem força, uma vez que o solvente compete com a FEQ para interagir com o analito. Em compensação, as interações hidrofóbicas tendem a predominar. Já quando se utiliza um solvente de baixa polaridade, como no modo normal de eluição, as interações 
hidrofóbicas entre o analito e a FEQ perdem força, novamente porque o solvente compete com a FEQ para interagir com o analito. Em compensação predominam as interações eletrostáticas (LÄMMERHOFER, 2010). Assim, durante o desenvolvimento de um método analítico enantiosseletivo é preciso avaliar qual FEQ será empregada e também a composição da fase móvel para então obter métodos seletivos, precisos e no menor tempo de análise possível.

A separação dos enantiômeros do TEB em diferentes matrizes, tais como frutas, vegetais e solo já foi reportada na literatura utilizando FEQ derivadas de amilose (LI et al., 2015; ZHAO et al., 2019), celulose (ZHANG et al., 2015) e ciclodextrinas (SHUANG et al., 2021), empregando CLAE-EM/EM (LI et al., 2015; ZHAO et al., 2019) e CLAE-DAD (ZHANG et al., 2015) tanto no modo normal, quanto no modo reverso de eluição. Porém, até o momento nenhum método analítico havia reportado a separação simultânea dos enantiômeros do TEB e TEBOH, o que é essencial para realizar o estudo de metabolismo in vitro proposto.

\subsection{Estudos enantiosseletivos de metabolismo in vitro}

A toxicidade dos praguicidas não se deve especificamente a uma única interação a nível molecular, mas sim a uma cascata de eventos que são desencadeados desde quando somos expostos a esses compostos, seja por via dérmica, oral, ou através da inalação, e que pode culminar com o surgimento ou não de um ou mais efeitos tóxicos (HODGSON, 2012).

Essa cascata de eventos envolve diversas etapas que vão desde a absorção, distribuição, metabolismo e por fim excreção do praguicida em si, ou dos metabólitos formados (ADME, Figura 3) (HODGSON, 2012), bem como as interações que ocorrem com as macromoléculas, como por exemplo o RNA, o DNA, e os mecanismos de ação tóxica gerados. 
Figura 3- Representação simplificada das etapas que compõem a toxicocinética de um xenobiótico.

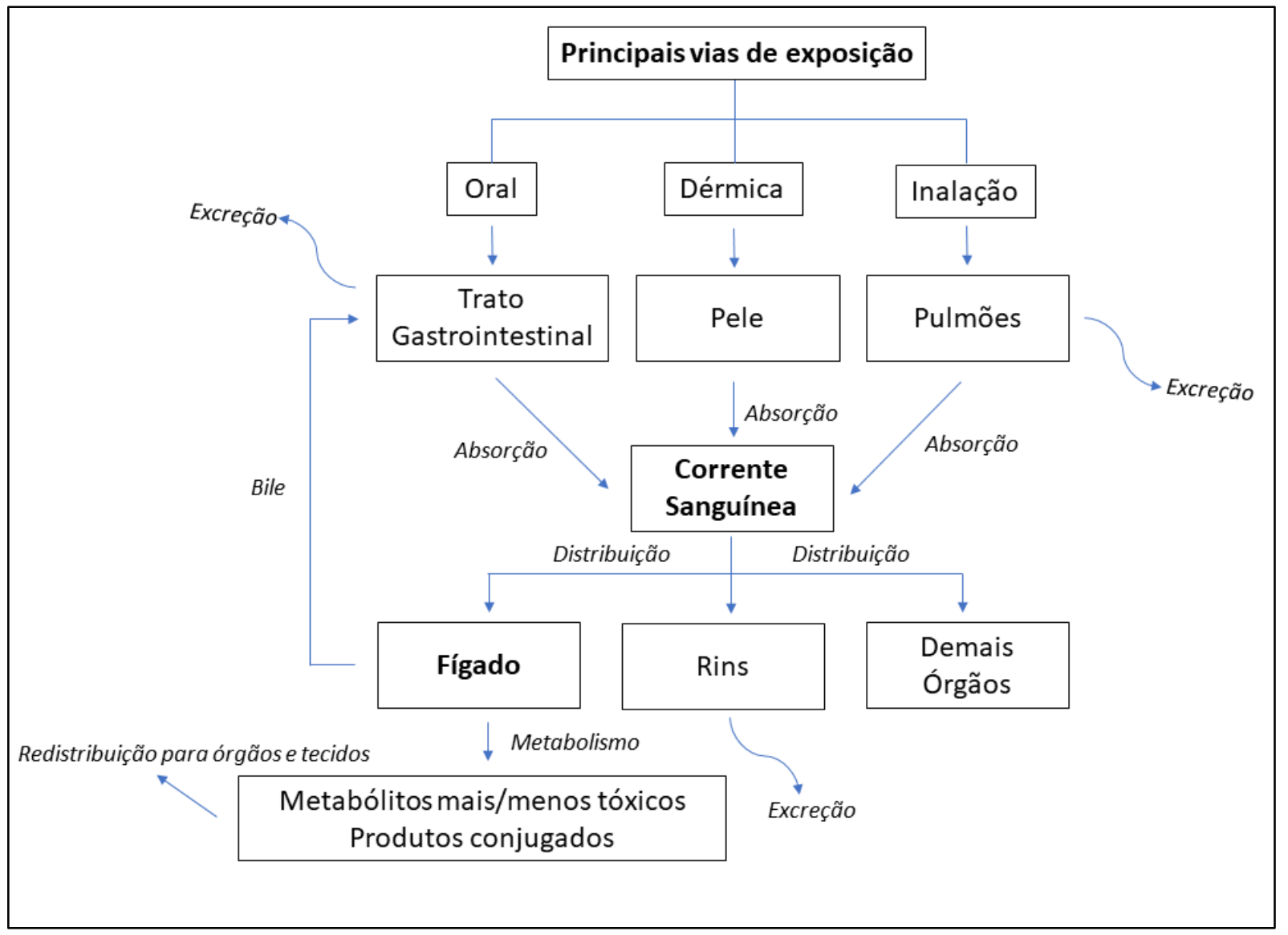

Fonte: Adaptado de HODGSON, 2010.

Avaliar o que acontece com um praguicida durante as etapas de ADME, em particular durante o seu metabolismo, é crucial para entender o seu modo de ação e sua possível toxicidade em organismos não-alvo.

O metabolismo, também chamado de biotransformação, é definido como o conjunto de reações catalisadas por enzimas que transformam os xenobióticos em compostos mais hidrofílicos, os chamados metabólitos, para que estes sejam excretados do organismo. Essas reações podem acontecer em diferentes órgãos, como rins, pulmão e cérebro, mas o principal órgão responsável pelo metabolismo é o fígado (ROSE; HODGSON, 2004a).

A importância do fígado fica evidente quando observamos que a absorção dos praguicidas pode ocorrer tanto através da pele, quanto das vias respiratórias e do trato gastrointestinal, e mesmo assim, após estes compostos atingirem a circulação sanguínea, eles tendem a passar pelo fígado, onde podem ser biotransformados (Figura 3). No fígado, o xenobiótico pode sofrer detoxificação, ou seja, ser metabolizado para formar metabólitos menos 
tóxicos do que o composto inicial, ou sofrer ativação, em que são produzidos metabólitos mais tóxicos (HODGSON, 2012).

As reações de metabolismo podem ser divididas em reações de fase I e de fase II. As reações de fase I são, predominantemente, reações de oxidação, redução e hidrólise e servem para introduzir grupos polares na molécula. Já as reações de fase II são reações de conjugação e nelas o produto obtido na fase I, ou a própria molécula original, sofre reações de conjugação com grupos endógenos hidrofílicos (ASHA; VIDYAVATHI, 2010).

A grande maioria dos praguicidas sofre inicialmente reações de fase I do metabolismo e essas reações podem ser catalisadas por diferentes famílias de enzimas, como das flavina monooxigenases, álcool ou aldeído desidrogenases, amina oxidases, mas principalmente a família de enzimas do CYP450 (ABASS et al., 2012).

As enzimas do CYP450 são uma superfamília de hemeproteínas presente no retículo endoplasmático de células de diferentes órgãos, mas principalmente de células hepáticas (ASHA; VIDYAVATHI, 2010). Existem diversas isoformas de enzimas do CYP450, sendo que as principais são a CYP3A4, CYP1A2, CYP2D6, CYP2C9, CYP2C19 e CYP2E1 (ABASS et al., 2012) e essas isoformas são conhecidas por catalisar o metabolismo de diversos praguicidas, como o diurom (ABASS et al., 2007), carbaril (TANG et al., 2002), fipronil (TANG et al., 2004), clorpirifós (TANG et al., 2001), metóxicloro (HU; KUPFER, 2002), dentre outros (HODGSON, 2010).

No caso de praguicidas quirais, o metabolismo tem a peculiaridade de poder ocorrer de maneira enantiosseletiva, uma vez que o corpo humano é um ambiente altamente estereoespecífico (ALI; ABOUL-ENEIN, 2004) e essas reações são catalisadas por enzimas constituídas por aminoácidos homoquirais (L-aminoácidos) (FUJII, 2002). Dessa forma, os enantiômeros de praguicidas quirais podem ser metabolizados por diferentes enzimas, podem ser metabolizados pela mesma enzima, mas com velocidades diferentes, além de outras situações (DE ALBUQUERQUE et al., 2018; MA; GAN; LIU, 2011)

Os estudos de metabolismo enantiosseletivo de praguicidas quirais envolvendo as enzimas do CYP450 podem ser realizados in vitro e tendem a ser mais fáceis de se executar do que estudos in vivo, além de utilizar pequenas quantidades dos compostos a serem avaliados e também serem mais baratos (STEPAN et al., 2013). Ademais, eles permitem colocar em prática a política dos 3Rs (reduce, replace, refine), reduzindo assim o emprego de animais em pesquisas toxicológicas (ESFA, 2014b), o que é também uma questão ética. 
Atualmente já existem diversos modelos in vitro derivados de células humanas que permitem investigar de maneira eficiente o metabolismo de praguicidas, como hepatócitos, pedaços do fígado, frações citosólicas e S9, isoformas recombinantes (rCYP450) e HLM (ASHA; VIDYAVATHI, 2010; ESFA, 2014b), sendo os HLM e rCYP450 os modelos in vitro mais utilizados.

Os HLM consistem em vesículas do retículo endoplasmático de hepatócitos preparadas através da homogeneização de pedaços do fígado seguido de etapas sucessivas de centrifugação diferenciada (ABASS, 2013). Esse modelo é muito útil para avaliar a estabilidade metabólica do composto, realizar estudos de inibição enzimática, identificar e quantificar metabólitos formados e determinar parâmetros cinéticos (ABASS, 2013). Já as rCYP450 são enzimas metabólicas recombinantes expressas em bactérias, leveduras ou células de insetos infectadas com baculovírus humano (ABASS, 2013; ESFA, 2014b) e são muito utilizadas para identificar as enzimas responsáveis por catalisar as reações de metabolismo.

Através dos ensaios in vitro utilizando modelos derivados de células humanas é possível determinar os perfis e os parâmetros cinéticos das reações de degradação dos enantiômeros de praguicidas quirais e identificar possíveis diferenças no metabolismo, bem como determinar alguns parâmetros toxicocinéticos após realizações de extrapolações in vitro-in vivo. Além disso, é possível determinar a rota metabólica, as enzimas responsáveis por catalisar o metabolismo e também avaliar possíveis interações com outros compostos, por exemplo fármacos (ESFA, 2014b).

\subsubsection{Cinética enzimática e extrapolações in vitro- in vivo}

As enzimas do CYP450 são catalisadores biológicos, ou seja, diminuem a energia de ativação das reações e aumentam a velocidade destas sem que ocorram mudanças no equilíbrio químico. A variação da velocidade dessas reações devido a mudanças de parâmetros experimentais, tais como a concentração de substrato e a concentração de proteína, é estudada por uma área da bioquímica chamada de cinética enzimática.

A grande maioria das reações catalisadas pelas enzimas do CYP450 pode ser descrita pela Equação 1, que representa a catálise por enzimas que tem um único sítio de ligação, ou múltiplos sítios independentes (SEIBERT; TRACY, 2014a). Nessas reações, a enzima (E) se liga rapidamente ao substrato (S), formando o complexo enzima-substrato (ES) e este se quebra para formar o produto $(\mathrm{P})$, no caso de reações metabólicas também chamado de metabólito, 
deixando a enzima novamente na sua forma livre (E) (SEGEL, 2013). E, S e ES estão em equilíbrio e, dessa forma, a velocidade de dissociação de $\mathrm{ES}$ para $\mathrm{E}+\mathrm{S}$ é muito maior do que a velocidade na qual ES se quebra para formar E + P (SEGEL, 2013).

$$
E+S \rightleftharpoons E S \rightarrow E+P
$$

sendo E - enzima; $\mathbf{S}$ - substrato; ES - complexo enzima- substrato e $\mathbf{P}$ - produto, ou no caso, o metabólito formado.

A velocidade inicial dessas reações segue o modelo de cinética mais simples que é o modelo de Michaelis-Menten. Esse modelo correlaciona a concentração de substrato ([S]) com a velocidade inicial da reação $\left(\mathrm{v}_{0}\right)$ através de dois parâmetros, $\mathrm{V}_{\max }$, que é a velocidade máxima da reação, e $K_{M}$ (constante de Michaelis-Menten), que é a concentração de substrato na qual $v_{0}$ é igual a metade de $\mathrm{V}_{\max }$ (HABENSCHUS, 2016).

$$
v_{0}=\frac{V_{\max } \cdot[S]}{K_{M}+[S]}
$$

sendo $\mathbf{v}_{\mathbf{0}}$ - velocidade inicial da reação enzimática; $\mathbf{V}_{\mathbf{m a x}}-$ velocidade máxima da reação enzimática; [S] - concentração de substrato e $\mathbf{K}_{\mathbf{M}}$ - constante de Michaelis-Menten (SEIBERT; TRACY, 2014a).

A equação de Michaelis- Menten (Equação 2) estabelece uma relação hiperbólica entre $\mathrm{v}_{0}$ e [S] (Figura 4A). Em concentrações baixas de substrato, $\mathrm{v}_{0}$ varia de forma linear com [S], já em concentrações muito maiores do que o valor de $K_{M}$ a enzima atinge condições de saturação e a partir daí, aumentos em [S] não provocam aumentos significativos na velocidade, e se diz então que a reação atingiu $\mathrm{V}_{\max }$ (SEIBERT; TRACY, 2014a).

Porém, algumas reações catalisadas pelas enzimas do CYP450 podem apresentar perfis cinéticos chamados de atípicos, principalmente pelo fato dos sítios ativos dessas enzimas serem maiores e menos específicos (SEIBERT; TRACY, 2014b). Devido a isso, o substrato pode se ligar a mais de um sítio ativo da enzima, ou mais de uma molécula de substrato pode se ligar a estes (SEIBERT; TRACY, 2014b). Dentre os perfis atípicos podemos citar o perfil bifásico. 
Figura 4- Gráficos de velocidade inicial da reação ( $\left.\mathrm{v}_{0}\right)$ vs a concentração de substrato ([S]) representando o perfil cinético de A) Michaelis-Menten e C) bifásico. B) e D) representam os gráficos de Eadie-Hofstee para uma cinética de Michaelis-Menten e para uma cinética bifásica, respectivamente.

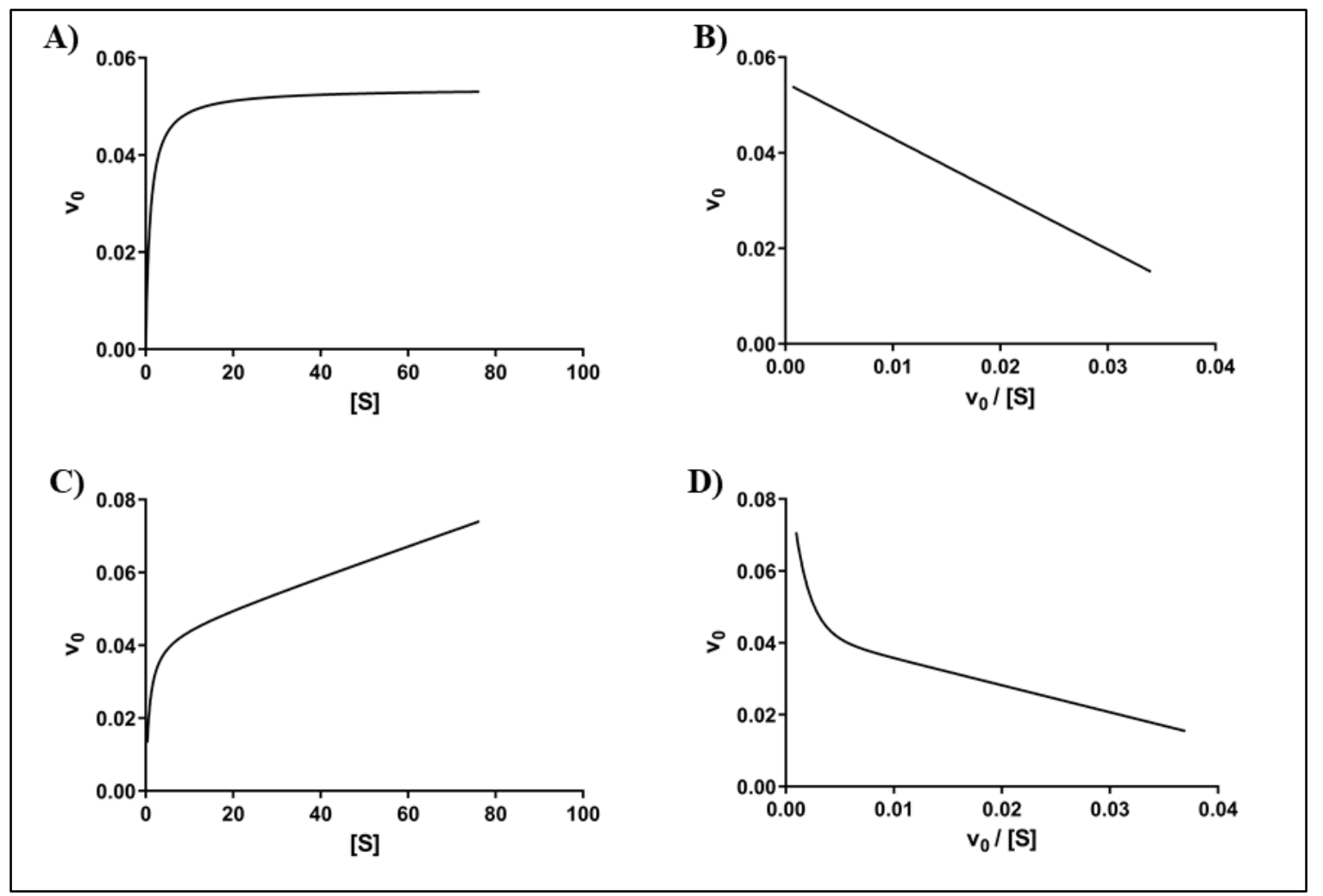

Fonte: Autoria própria

Na cinética bifásica (Figura 4C), o perfil é caracterizado por, no início, apresentar um aumento proporcional em $\mathrm{v}_{0}$ à medida que se aumenta $[\mathrm{S}]$, assim como ocorre na cinética de Michaelis- Menten. Porém, ao contrário da cinética de Michaelis-Menten, que passa a ser de ordem zero em $[\mathrm{S}]$ muito maiores do que o valor de $\mathrm{K}_{\mathrm{M}}$, na cinética bifásica a saturação não é alcançada. Assim, mesmo em [S] muito altas, observa-se ainda uma relação linear entre $\mathrm{v}_{0}$ e [S], o que pode ser descrito pela Equação 3 (SEIBERT; TRACY, 2014b). Esse tipo de perfil cinético normalmente é observado quando a reação é catalisada por enzimas com múltiplos sítios de ligação, ou quando a reação é catalisada por diversas enzimas.

$$
v_{0}=\frac{\left(V_{\max 1} \cdot[S]\right)+\left(\frac{V \max _{2}}{K_{M 2}} \cdot[S]^{2}\right)}{K_{M 1}+[S]}
$$

sendo $\mathbf{v}_{\mathbf{0}}$ - velocidade inicial da reação enzimática; [S] - concentração de substrato; $\mathbf{V}_{\max \mathbf{1}}$ - velocidade máxima da reação catalisada pela enzima ou sítio de ligação que tem alta afinidade pelo substrato; $\mathbf{K}_{\mathbf{M} 1}$ - constante de Michaelis-Menten relacionada a enzima ou sítio de ligação que tem alta afinidade pelo substrato; $\mathbf{V}_{\max 2}$ - velocidade máxima da reação catalisada pela enzima ou sítio de ligação que tem baixa afinidade pelo substrato e $\mathbf{K}_{\mathbf{M} 2}$ - constante de Michaelis-Menten relacionada a enzima ou sítio de ligação que tem baixa afinidade pelo substrato (SEIBERT; TRACY, 2014b). 
Muitas vezes, é difícil caracterizar qual o perfil cinético de uma reação apenas observando o gráfico de $\mathrm{v}_{0} v s$. [S], pois desvios da cinética de Michaelis-Menten costumam acontecer em baixas concentrações de substrato e podem não ser aparentes no gráfico direto (BRIAN HOUSTON; KENWORTHY; GALETIN, 2003). Então, gráficos de Eadie-Hofstee, que correlacionam $\mathrm{v}_{0} v s . \mathrm{v}_{0} /[\mathrm{S}]$, podem ser empregados como ferramentas de diagnóstico. Tais gráficos distribuem melhor os dados obtidos, tornando mais fácil visualizar os parâmetros e detectar perfis atípicos (BRIAN HOUSTON; KENWORTHY; GALETIN, 2003).

As Figura 4B e 4D mostram os gráficos de Eadie-Hofstee para a cinética de MichaelisMenten e para a cinética bifásica, respectivamente. É possível observar que os perfis são bem distintos e é mais fácil visualizar a contribuição de dois componentes para a cinética bifásica, o de alta e o de baixa afinidade pelo substrato, enquanto há a contribuição de apenas um para a cinética de Michaelis-Menten (SEIBERT; TRACY, 2014b).

Avaliar corretamente qual é o perfil cinético de uma reação catalisada por enzimas é essencial para a obtenção de valores corretos de $K_{M}$ e $V_{\text {max }}$. Esses valores são utilizados para a determinação do clearance hepático intrínseco in vitro $\left(\mathrm{CL}_{\mathrm{int}}\right.$, in vitro), que é uma medida da capacidade que o fígado tem de depurar um determinado composto quando não há influência de outros parâmetros fisiológicos, tais como o fluxo sanguíneo hepático e ligações às proteínas plasmáticas, e é obtido pela relação entre $\mathrm{V}_{\max }$ e $\mathrm{K}_{\mathrm{M}}$ (BRIAN HOUSTON; KENWORTHY; GALETIN, 2003).

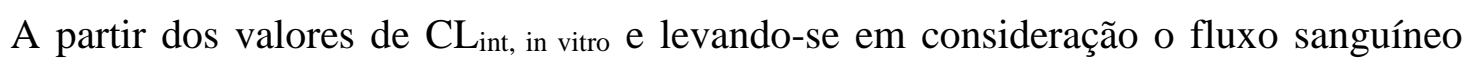
hepático e a porcentagem de ligação do composto às proteínas plasmáticas e microssomais, podem ser feitas extrapolações in vitro-in vivo para predizer alguns parâmetros toxicocinéticos, tais como o clearance hepático $\left(\mathrm{CL}_{\mathrm{H}}\right)$ e a taxa de extração hepática $\left(\mathrm{E}_{\mathrm{H}}\right)$.

$\mathrm{CL}_{\mathrm{H}}$ está associado à eficiência do processo de depuração de um xenobiótico pelo fígado, sendo que valores de $\mathrm{CL}_{\mathrm{H}}$ próximos a $20 \mathrm{~mL} \mathrm{~min}^{-1} \mathrm{~kg}^{-1}$, que equivale ao fluxo sanguíneo hepático, indicam que praticamente todo composto que chega ao fígado pode vir a ser removido da corrente sanguínea através do metabolismo hepático (BOWMAN; BENET, 2018; DAMRE; IYER, 2012). Já $E_{H}$ indica a fração do xenobiótico que é depurada durante a sua passagem pelo órgão, considerando uma ingestão oral. Uma taxa de extração hepática próxima a 100\% sugere que o composto pode ser metabolizado quase que totalmente pelo fígado já em sua primeira passagem pelo órgão, chegando uma pequena parcela deste na circulação sistêmica, ou seja, o composto sofre um alto efeito de primeira passagem (BOWMAN; BENET, 2018; DAMRE; IYER, 2012). 
Extrapolações in vitro-in vivo são importantes para predizer o que pode vir acontecer in vivo em casos de exposição a um praguicida, e também se ocorre enantiosseletividade no caso de praguicidas quirais. Por questões éticas, diferente do que acontece com fármacos em desenvolvimento, praguicidas não podem ser administrados em humanos para então serem determinados os parâmetros toxicocinéticos. Dessa forma, através de ensaios in vitro e fazendo extrapolações é possível diminuir o uso de animais nesses estudos ou até mesmo selecionar o modelo animal mais adequado, uma vez que existem diferenças entre a atividade catalítica das isoformas das enzimas do CYP450 expressas em animais e as expressas em humanos (MARTIGNONI; GROOTHUIS; DE KANTER, 2006). Sendo assim, extrapolações in vitro- in vivo tem ganhado destaque.

\subsubsection{Estudos de Fenotipagem}

O clearance, ou seja, a depuração de um praguicida no organismo humano, pode acontecer através da excreção desse composto sem que ocorram modificações em sua estrutura química ou então através de reações de metabolismo que levam a formação de outros compostos chamados metabólitos (STEVENS; WIENKERS, 2003).

Diferentes reações de metabolismo de praguicidas são catalisadas pelas isoformas das enzimas do CYP450, principalmente a CYP1A2, CYP2B6, CYP2C8, CYP2C9, CYP2C19, CYP2D6, CYP2E1, CYP3A4 e CYP3A5 (NIROGI et al., 2015). A CYP1A2, por exemplo, catalisa a oxidação da cis-permetrina (SCOLLON et al., 2009) e a $N$-demetilação do diurom (ABASS et al., 2007), enquanto que a CYP2C9 catalisa a oxidação do esfenverelato (GODIN et al., 2007) e a CYP3A4 catalisa a oxidação do fipronil (CARRÃO et al., 2019).

Nos ensaios para a elucidação da rota metabólica de um determinado praguicida, além de determinar quais famílias de enzimas catalisam as reações, é primordial determinar também quais isoformas em específico estão envolvidas no processo e esses estudos são denominados estudos de fenotipagem ou mapeamento enzimático (WHITE, 2012).

Os estudos de fenotipagem ou mapeamento enzimático envolvendo as enzimas do CYP450 testam a capacidade que diversas isoformas têm de metabolizar um determinado composto (ZHANG et al., 2007). Esses estudos são muito importantes, pois através de seus resultados consegue-se predizer a rota metabólica e também possíveis interações indesejáveis entre xenobióticos. 
Dentre as interações indesejáveis entre xenobióticos podemos citar aquelas causadas pela inibição ou indução da atividade das enzimas do CYP450. Essas interações podem causar efeitos adversos no organismo humano, principalmente se o composto é metabolizado por uma única isoforma (STEVENS; WIENKERS, 2003), uma vez que a inibição da atividade enzimática dessa isoforma leva a um metabolismo em menor extensão, podendo prejudicar a excreção do xenobiótico e causar um acúmulo no organismo.

Além disso, algumas enzimas do CYP450 apresentam variantes alélicos em seus genes, fenômeno chamado de polimorfismo. O polimorfismo faz com que tais enzimas possam ser expressas de diferentes formas na população, ou seja, uma determinada isoforma pode ser expressa, em algumas pessoas, com atividade catalítica reduzida, em outras com nenhuma atividade, ou então determinadas isoformas podem ser expressas em excesso, resultando em uma alta atividade catalítica (WHITE, 2012).

O polimorfismo também faz com que a extensão do metabolismo possa ser variável entre grupos étnicos (WHITE, 2012) e tal variação deve ser levada em consideração quando está sendo avaliado o risco de exposição a um determinado praguicida. Já se sabe, por exemplo, que a CYP2C19 e a CYP2D6 são isoformas que apresentam polimorfismo (OGILVIE; USUKI; YERINO, 2008). Portanto, se um praguicida é metabolizado por apenas uma dessas isoformas, o risco de exposição de parte dos caucasianos e asiáticos a esse composto pode ser maior, uma vez que essas pessoas são geneticamente deficientes nessas enzimas e, consequentemente, o metabolismo ocorrerá em menor extensão (OGILVIE; USUKI; YERINO, 2008).

Existem dois métodos in vitro comumente utilizados nos estudos de fenotipagem: um que emprega rCYP450 individuais e outro que emprega HLM ou hepatócitos juntamente com compostos químicos ou anticorpos que inibem seletivamente a atividade de isoformas específicas (FDA, 2020a), sendo aconselhável a realização de ensaios utilizando ambos os métodos e também a correlação entre os resultados (FDA, 2020a).

No primeiro caso, o xenobiótico cujo metabolismo está sendo avaliado é incubado com as rCYP450 individuais na presença do cofator NADPH e então é monitorado o seu consumo ou então a formação de metabólitos (SINZ, 2012). Com isso, as atividades enzimáticas são determinadas e aquelas isoformas capazes de metabolizar o composto em questão são confirmadas (OGILVIE; USUKI; YERINO, 2008).

Já no segundo caso, o xenobiótico a ser avaliado é incubado com HLM ou hepatócitos e NADPH na presença e na ausência de determinados compostos químicos ou anticorpos que diminuem ou eliminam seletivamente a atividade de isoformas específicas. Assim, a 
contribuição de cada isoforma pode ser determinada (SINZ, 2012) e aquelas isoformas cujas atividades enzimáticas tiveram maiores porcentagens de inibição são consideradas as que contribuem mais para o metabolismo.

Atualmente, segundo a agência americana reguladora de alimentos e medicamentos (FDA, Food and Drug Administration), os estudos de fenotipagem envolvendo fármacos quirais devem ser feitos avaliando individualmente cada um dos enantiômeros com o intuito de entender e constatar uma possível diferença no metabolismo de cada um destes (FDA, 2020a). Tendo isso como base, o mesmo pode ser estendido para o caso de praguicidas quirais, pois os enantiômeros de praguicidas quirais podem ser metabolizados por isoformas distintas, sendo importante essa investigação (BURA et al., 2019).

\subsection{Estudos enantiosseletivos de inibição enzimática: interação praguicida- fármaco}

As pessoas estão em contato diário com diferentes tipos de xenobióticos e essa exposição se dá por diversas rotas, como por exemplo via oral, dérmica e também através da inalação. Tal exposição pode ocorrer de maneira desejada e consciente, como quando medicamentos são utilizados para tratar ou prevenir alguma doença, ou de maneira indesejada e inconsciente, quando alimentos ou água contaminados com praguicidas são ingeridos, quando trabalhadores rurais são expostos durante a aplicação de agroquímicos nas lavouras, e até mesmo, quando o ar contaminado com poluentes é inalado.

Devido ao contato simultâneo com xenobióticos de diferentes classes, é muito provável o surgimento no nosso organismo de interações metabólicas entre esses compostos, principalmente devido a efeitos que um deles pode provocar no metabolismo hepático do outro (ROSE; HODGSON, 2004b)

As reações de fase I do metabolismo hepático de xenobióticos são catalisadas principalmente pela família de enzimas do CYP450. Dentre as principais isoformas do CYP450 podem ser destacadas a CYP1A2, CYP2C9, CYP2C19, CYP2D6, CYP2E1 e CYP3A4/5. Juntas, essas isoformas são responsáveis por, aproximadamente, $80 \%$ das reações de metabolismo de fármacos catalisadas pela família do CYP450 (ARORA et al., 2015). Além disso, estima-se que essas isoformas sejam responsáveis por catalisar o metabolismo de mais de $70 \%$ dos praguicidas (ABASS et al., 2012).

Os xenobióticos, além de serem substratos dessas isoformas, também podem atuar como inibidores de sua atividade enzimática ou como indutores de sua expressão gênica (ABASS; 
PELKONEN, 2013; HODGSON, 2004). Já é conhecido que praguicidas podem inibir a atividade das enzimas do CYP450 (ABASS; PELKONEN, 2013; CARRÃO et al., 2019; FONSECA et al., 2019), e por isso eles podem interferir nas reações de metabolismo de fase I de outros xenobióticos, como por exemplo fármacos, causando assim interações praguicidafármacos (ABASS; PELKONEN, 2013; CARRÃO et al., 2019; FONSECA et al., 2019). O termo interação, nesse caso, se refere a situações em que os compostos influenciam na toxicidade uns dos outros e os efeitos conjuntos podem ser diferentes do efeitos individuais previstos para eles (HERNÁNDEZ; GIL; LACASAÑA, 2017).

Uma interação causada pela inibição do metabolismo de um fármaco pode provocar um aumento na sua concentração plasmática, e consequentemente desencadear possíveis efeitos tóxicos, principalmente se o fármaco em uso tem uma janela terapêutica estreita. Além disso, alguns estudos com trabalhadores rurais sugerem que interações praguicida-fármacos podem estar relacionadas com problemas de saúde apresentados por esses trabalhadores, como por exemplo o surgimento de doença de Hodgkin, leucemia, câncer de próstata, estômago, pele, etc (ROSE et al., 2005).

Dessa forma, é muito importante avaliar se um praguicida pode inibir a atividade das enzimas do CYP450 e qual é o seu potencial inibitório. No caso de praguicidas quirais, essa avaliação ganha ainda mais destaque, uma vez que pode acontecer de forma enantiosseletiva, com um enantiômero tendo maior potencial inibitório do que o outro (DE ALBUQUERQUE et al., 2020).

Os estudos de inibição das enzimas do CYP450 podem ser feitos in vitro utilizando HLM. Para isso, monitora-se a velocidade de formação de metabólitos de reações específicas que são catalisadas pelas isoformas do CYP450, na presença e na ausência do possível inibidor e do cofator NADPH (Tabela 1, FDA, 2020b). As reações específicas a serem monitoradas devem ter os parâmetros cinéticos $\left(\mathrm{K}_{\mathrm{M}} \mathrm{e} \mathrm{V}_{\max }\right)$ bem definidos e os substratos devem ser escolhidos de acordo com a sua seletividade, ou seja, o substrato deve ser predominantemente metabolizado pela isoforma avaliada. Os resultados obtidos desses ensaios permitem a determinação de importantes parâmetros relacionados a inibição de uma enzima, tais como a concentração do composto que inibe em 50\% a atividade da isoforma (IC50), além dos mecanismos e das constantes de inibição (HABENSCHUS, 2016). 
Tabela 1- Reações específicas catalisadas pelas isoformas do CYP450 que podem ser monitoradas nos estudos in vitro de inibição enzimática e os respectivos metabólitos formados.

\begin{tabular}{|c|c|c|}
\hline Isoformas & Reações específicas & Metabólitos \\
\hline \multirow[t]{2}{*}{ CYP1A2 } & $O$-desetilação da fenacetina & Acetaminofeno \\
\hline & $O$-desetilação da etoxiresorufina & Resorufina \\
\hline \multirow[t]{2}{*}{ CYP2B6 } & Hidroxilação da bupropiona & Hidroxibupropiona \\
\hline & 8-hidroxilação do efavirez & 8-hidroxiefavirenz \\
\hline \multirow[t]{2}{*}{ CYP2C8 } & 6 $\alpha$-hidroxilação do paclitaxel & $6 \alpha$-hidroxipaclitaxel \\
\hline & $N$-desetilação da almoaquina & $N$-desetilalmoaquina \\
\hline \multirow[t]{2}{*}{ CYP2C9 } & 7-hidroxilação da $S$-varfarina & 7-hidroxi-S-varfarina \\
\hline & 4'-hidroxilação do diclofenaco & 4'-hidroxidiclofenaco \\
\hline CYP2C19 & 4'-hidroxilação da $S$-mefenitoína & 4'-hidroxi-S-mefenitoína \\
\hline \multirow[t]{2}{*}{ CYP2D6 } & 1'-hidroxilação do bufuralol & 1'-hidroxibufuralol \\
\hline & $O$-desmetilação do dextrometorfano & Dextrorfano \\
\hline \multirow[t]{2}{*}{ CYP2E1 } & 6-hidroxilação da clorzoxazona & 6-hidroxiclorzoxazona \\
\hline & 4-hidroxilação da anilina & 4-hidroxianilina \\
\hline \multirow{3}{*}{ CYP3A4/5* } & 1'-hidroxilação do midazolam & 1'-hidroximidazolam \\
\hline & $6 \beta$-hidroxilação da testosterona & $6 \beta$-hidroxitestosterona \\
\hline & Oxidação da nifedipina & deidronifenidipina \\
\hline
\end{tabular}

* É recomendado utilizar dois substratos estruturalmente não similares para avaliar a inibição da CYP3A4/5. Fonte: Adaptado de FDA, 2020b.

A inibição da atividade das enzimas do CYP450 pode ocorrer tanto de maneira direta, quanto de maneira tempo-dependente. A inibição direta ocorre assim que o composto se liga à enzima e sem a necessidade de etapas prévias de biotransformação. Já na inibição tempodependente, o potencial inibitório do composto aumenta com o tempo de interação entre ele e a enzima, indicando, na maioria dos casos, a necessidade de etapas prévias de biotransformação (FONSECA, 2018; OGILVIE; USUKI; YERINO, 2008).

A inibição tempo-dependente acontece devido a interações quase-irreversíveis entre a enzima e o inibidor, ou interações irreversíveis que são dependentes do metabolismo. Nesses casos, a enzima perde a sua atividade, sendo necessário a síntese de novas enzimas para desempenharem a mesma função. Já as inibições diretas ocorrem devido a interações reversíveis entre a enzima e o inibidor e são mais frequentes do que as inibições tempodependentes (HABENSCHUS, 2016; OGILVIE; USUKI; YERINO, 2008). 
De maneira geral, a inibição reversível acontece devido a rápida associação e dissociação entre a enzima e o inibidor (ROSE; HODGSON, 2004b) através de ligações nãocovalentes, tais como ligações de hidrogênio, interações hidrofóbicas e ligações iônicas (KRAMER; TRACY, 2012). Como o próprio nome já diz, tal inibição é reversível e pode ser desfeita por processos como diálise, ou então diluição, e a enzima recupera a sua atividade catalítica. Esse tipo de inibição ocorre por quatro mecanismos distintos, sendo estes a inibição competitiva, não-competitiva, mista (competitiva/não-competitiva) e incompetitiva (RING; WRIGHTON; MOHUTSKY, 2014).

A inibição competitiva é o mecanismo mais observado para a inibição das enzimas do CYP450 (VOLAK; GREENBLATT; VON MOLTKE, 2007). Nesse caso, o substrato e o inibidor competem para se ligar ao sítio ativo da enzima livre (E), ou seja, apenas um deles pode se ligar exclusivamente ao sítio ativo.

Caso o substrato se ligue, ocorre a formação do complexo ES e a reação ocorre na mesma velocidade que ocorreria na ausência de inibidor. Portanto a reação atinge a mesma $\mathrm{V}_{\max }$. Porém, caso o inibidor se ligue ao sítio ativo, acontece a formação do complexo enzimainibidor (EI) e a enzima se torna incapaz de catalisar a reação de depuração do substrato, havendo um aumento de $\mathrm{K}_{\mathrm{M}}$ (RING; WRIGHTON; MOHUTSKY, 2014).

Na inibição não-competitiva o inibidor se liga a um sítio da enzima que é diferente do sítio ativo ao qual se liga o substrato (OGILVIE; USUKI; YERINO, 2008). Ele pode se ligar tanto a enzima livre, formando o complexo EI, quanto ao complexo ES, formando o complexo enzima-substrato-inibidor (ESI) e essas ligações acontecem com a mesma afinidade. Esse mecanismo de inibição é caracterizado por uma diminuição de $\mathrm{V}_{\max }$ sem que ocorram mudanças em KM (RING; WRIGHTON; MOHUTSKY, 2014).

Na inibição mista (competitiva/não-competitiva) o inibidor se liga tanto a enzima livre, formando o complexo EI, quanto a ES, formando o complexo ESI. Porém diferente do que ocorre na inibição não-competitiva, essa ligação ocorre com afinidades diferentes (RING; WRIGHTON; MOHUTSKY, 2014). Além disso, esse mecanismo é caracterizado por uma diminuição de $\mathrm{V}_{\max }$ e aumento de $\mathrm{K}_{\mathrm{M}}$.

Por fim, na inibição incompetitiva o inibidor se liga à enzima quando o substrato já está ligado, estabilizando o complexo ES e formando o complexo ESI, ou seja, o inibidor não tem afinidade pela enzima livre. Nesse tipo de inibição ocorre uma diminuição de $V_{\text {max }}$ da reação e também de $\mathrm{K}_{\mathrm{M}}$ (RING; WRIGHTON; MOHUTSKY, 2014). Ademais, esse mecanismo é 
raramente observado nos estudos de inibição das enzimas do CYP450 (VOLAK; GREENBLATT; VON MOLTKE, 2007)

Outro importante parâmetro a ser determinado nos estudos de inibição reversível, além do mecanismo de inibição, é a afinidade com que o inibidor se liga à enzima (HABENSCHUS, 2016). Esse parâmetro é denominado $K_{i}$, constante de inibição reversível, e é definido como sendo a constante de dissociação do complexo EI, ou no caso de uma inibição mista, também de ESI $\left(\alpha K_{i}\right)$ (OGILVIE; USUKI; YERINO, 2008). Quanto menor o valor de $\mathrm{K}_{\mathrm{i}}$, maior a afinidade da enzima pelo inibidor, ou seja, maior o potencial inibitório do composto em estudo, e no caso de praguicidas, maior a probabilidade de que ocorram interações praguicida-fármaco.

Baseado no exposto e no fato de que as informações a respeito dos efeitos dos enantiômeros do TEB no corpo humano ainda são muito escassas, investigar a inibição in vitro enantiosseletiva das enzimas do CYP450 pelo TEB é importante, pois fornecerá informações valiosas a respeito do risco de exposição do homem ao TEB e de prováveis interações TEBfármacos. 


\section{CONCLUSÕES}

O uso de praguicidas quirais, em geral, pode representar riscos para a saúde humana, uma vez que estamos expostos a esses compostos diariamente, por exemplo, através da alimentação ou exposição laboral, e os enantiômeros de praguicidas quirais podem apresentar propriedades biológicas distintas, ou seja, enquanto um pode ser inofensivo para o organismo humano, o outro pode causar danos. Nesse contexto, através de estudos in vitro enantiosseletivos de metabolismo de fase I e estudos de inibição da atividade das enzimas do CYP450, bem como através de extrapolações in vitro-in vivo, o presente trabalho obteve importantes resultados que ajudam a predizer a toxicocinética do TEB em humanos, além de resultados que indicam possíveis interações TEB-fármacos.

De acordo com os dados apresentados, o TEB sofre metabolismo de fase I catalisado pelas enzimas do CYP450 presentes nos HLM, havendo a formação de seu metabólito majoritário TEBOH. Múltiplas isoformas do CYP450 são capazes de catalisar essa reação, com destaques para a CYP3A4 e CYP2C9. Então, considerando a contribuição do metabolismo hepático para a eliminação do TEB do organismo humano, a existência de diversas vias de metabolismo hepático (diversas enzimas) possíveis faz com que o acúmulo desse praguicida se torne mais difícil.

Além disso, o TEB pode ser depurado enantiosseletivamente pelo fígado humano, com degradação preferencial do $S$-(+)-TEB, seguido pelo rac-TEB e $R$-(-)-TEB. Os valores de $\mathrm{E}_{\mathrm{H}}$ $(<30 \%)$ sugeriram que se o TEB for ingerido, o efeito de primeira passagem pelo fígado pode não ser efetivo para diminuir a sua concentração inicial na corrente sanguínea, ou seja, o TEB pode chegar até a circulação sistêmica, principalmente o $R$-(-)-TEB, e causar outros efeitos no organismo que devem ser investigados. Esses valores de $\mathrm{E}_{\mathrm{H}}$ também indicam que a depuração total do TEB ocorrerá apenas após sucessivas passagens pelo fígado, ou após o metabolismo hepático ser catalisado por outras famílias de enzimas, ou então ocorrer em outros órgãos, como os rins.

Já com relação aos ensaios enantiosseletivos de inibição da atividade das enzimas do CYP450 pelo TEB, os resultados mostraram que o rac-TEB, $R$-(-)-TEB e $S$-(+)-TEB inibiram a atividade enzimática da CYP3A4/5, CYP2C9, CYP2D6 e CYP2C19 e, apesar da inibição ser enantiosseletiva para essas três últimas isoformas, ela não foi suficiente para que houvesse diferença significativa de potencial inibitório entre a mistura racêmica e os enantiômeros isolados. 
Assim, os mecanismos e valores das constantes de inibição foram determinados empregando o rac-TEB e mostraram que este é um inibidor reversível misto (competitivo- não competitivo) forte da CYP3A4/5 e CYP2C9 e um inibidor competitivo moderado e forte da CYP2D6 e CYP2C19, respectivamente. Além disso, os valores das constantes de inibição indicaram que o risco de interações $r a c$-TEB-fármacos não pode ser descartado, principalmente interações com fármacos metabolizados majoritariamente pela CYP3A4/5, CYP2C9 e CYP2C19.

Dessa forma, todas essas informações juntas contribuem para a avaliação do risco de exposição humana ao praguicida quiral TEB, de maneira enantiosseletiva, e indicam que estes riscos não devem ser negligenciados, sendo necessário, assim, um maior controle. 


\section{Referências Bibliográficas}

ABASS, K. et al. Characterization of diuron $N$-demethylation by mammalian hepatic microsomes and cDNA-expressed human cytochrome P450 enzymes. Drug Metabolism and Disposition, 2007.

ABASS, K. et al. Metabolism of Pesticides by Human Cytochrome P450 Enzymes In Vitro A Survey. In: Insecticides - Advances in Integrated Pest Management. [s.l: s.n.].

ABASS, K. M. From in vitro hepatic metabolic studies towards human health risk assessment: Two case studies of diuron and carbosulfan. Pesticide Biochemistry and Physiology, 2013.

ABASS, K.; PELKONEN, O. The inhibition of major human hepatic cytochrome P450 enzymes by 18 pesticides: Comparison of the $N$-in-one and single substrate approaches. Toxicology in Vitro, 2013.

ALI, I.; ABOUL-ENEIN, H. Y. Chiral Pollutants: Biotransformation, Biodegradation and Metabolism. In: Chiral Pollutants: Distribution, Toxicity and Analysis by Chromatography and Capillary Electrophoresis. [s.l: s.n.].

AMBIENTE, M. DO M. Produtos Agrotóxicos. Disponível em: $<$ https://www.mma.gov.br/seguranca-quimica/gestao-das-substancias-quimicas/produtosagrotóxicos.html>. Acesso em: 7 jun. 2020.

ANVISA. Programa de Análise de Resíduos de Agrotóxicos em Alimentos (PARA): relatório das amostras analisadas no período de 2017-2018. Agência Nacional de Vigilância Sanitária, 2019.

ARORA, S. et al. In vivo prediction of CYP-mediated metabolic interaction potential of formononetin and biochanin A using in vitro human and rat CYP450 inhibition data. Toxicology Letters, 2015.

ASHA, S.; VIDYAVATHI, M. Role of human liver microsomes in in vitro metabolism of drugs-A review. Applied Biochemistry and Biotechnology, 2010.

BADAWI, N. et al. Degradation and sorption of the fungicide tebuconazole in soils from golf greens. Environmental Pollution, 2016.

BAUGROS, J. B. et al. Multiresidue analytical methods for the ultra-trace quantification of 33 priority substances present in the list of REACH in real water samples. Analytica Chimica Acta, 2008.

BENDING, G. D.; RODRÍGUEZ-CRUZ, M. S.; LINCOLN, S. D. Fungicide impacts on microbial communities in soils with contrasting management histories. Chemosphere, 2007.

BONNER, M. R.; ALAVANJA, M. C. R. Pesticides, human health, and food security. Food and Energy Security, v. 6, n. 3, p. 89-93, 1 ago. 2017.

BOWMAN, C. M.; BENET, L. Z. An examination of protein binding and protein-facilitated 
uptake relating to in vitro-in vivo extrapolation. European Journal of Pharmaceutical Sciences, v. 123, p. 502-514, 15 out. 2018.

BRIAN HOUSTON, J.; KENWORTHY, K.; GALETIN, A. Typical and Atypical Enzyme Kinetics. In: Drug Metabolizing Enzymes. [s.l: s.n.].

BURA, L. et al. Guidance of EFSA on risk assessments for active substances of plant protection products that have stereoisomers as components or impurities and for transformation products of active substances that may have stereoisomers. EFSA Journal, 2019.

CARGNIN, M. C. DOS S.; ECHER, I. C.; SILVA, D. R. DA. Fumicultura : uso de equipamento de proteção individual e intoxicação por agrotóxico. 2017.

CARRÃO, D. B. et al. Evaluation of the enantioselective in vitro metabolism of the chiral pesticide fipronil employing a human model: Risk assessment through in vitro-in vivo correlation and prediction of toxicokinetic parameters. Food and Chemical Toxicology, v. 123, p. 225-232, 1 jan. 2019.

CARRÃO, D. B. et al. Enantioseparation of pesticides: A critical review. TrAC - Trends in Analytical Chemistry, 2020.

CARVALHO, D. F. P. et al. Determination of environmental exposure to ddt by human hair analysis in Santos and São Vicente Estuary, São Paulo, Brazil. Orbital, 2018.

CHANKVETADZE, B. Liquid chromatographic separation of enantiomers. In: Liquid Chromatography: Applications: Second Edition. [s.1.] Elsevier Inc., 2017. v. 2p. 69-86.

CHEN, J. et al. Individual and combined effects of herbicide tribenuron-methyl and fungicide tebuconazole on soil earthworm Eisenia fetida. Scientific Reports, 2018.

CLASEN, B. et al. Bioaccumulation and oxidative stress caused by pesticides in Cyprinus carpio reared in a rice-fish system. Science of the Total Environment, v. 626, p. 737-743, jun. 2018.

CUI, N. et al. Chiral triazole fungicide tebuconazole: enantioselective bioaccumulation, bioactivity, acute toxicity, and dissipation in soils. Environmental Science and Pollution Research, 2018.

DAMRE, A. A.; IYER, K. R. The Significance and Determination of Plasma Protein Binding. In: Encyclopedia of Drug Metabolism and Interactions. Hoboken, NJ, USA: John Wiley \& Sons, Inc., 2012. p. 1-18.

DE ALBUQUERQUE, N. C. P. et al. Metabolism studies of chiral pesticides: A critical review. Journal of Pharmaceutical and Biomedical Analysis, 2018.

DE ALBUQUERQUE, N. C. P. et al. Risk assessment of the chiral pesticide fenamiphos in a human model: Cytochrome P450 phenotyping and inhibition studies. Food and Chemical Toxicology, v. 146, 2020.

DE CAMPOS LOURENÇO, T.; CASSIANO, N. M.; CASS, Q. B. Fases estacionárias quirais 
para cromatografia líquida de alta eficiência. Quimica Nova, 2010.

DE LUCCA, D. et al. Farm workers' vulnerability due to the pesticide use on vegetable plantations in the Northeastern region of Brazil. Rev. bras. Saúde ocup, v. 37, n. 125, p. 8998, 2012.

DE SOUZA, R. M. et al. Occurrence, impacts and general aspects of pesticides in surface water: A review. Process Safety and Environmental Protection, 2020.

DEFRA. Differential Metabolism of Chiral Compounds. 2002.

ESFA. Conclusion on the peer review of the pesticide risk assessment of the active substance tebuconazole. EFSA Journal, 2014a.

ESFA. Modern methodologies and tools for human hazard assessment of chemicals. EFSA Journal, 2014b.

EUROPEAN CHEMICAL AGENCY. Committee for Risk Assessment RAC Opinion proposing harmonised classification and labelling at EU level of tebuconazole. [s.l: s.n.]. Disponível em: <http://echa.europa.eu/harmonised-classification-and-labelling-consultation>.

FDA. In Vitro Drug Interaction Studies-Cytochrome P450 Enzyme-and Transporter-Mediated Drug Interactions Guidance for Industry. FDA: Silver Spring, n. January, p. 43, 2020a.

FDA. Drug Development and Drug Interactions: Table of Substrates, Inhibitors and Inducers.

http://www.fda.gov/Drugs/DevelopmentApprovalProcess/DevelopmentResources/DrugIntera ctionsLabeling/ucm093664.htm\#4. Disponível em: <https://www.fda.gov/drugs/druginteractions-labeling/drug-development-and-drug-interactions-table-substrates-inhibitors-andinducers>. Acesso em: 21 jul. $2020 \mathrm{~b}$.

FONSECA, F. S. Análise enantiosseletiva do praguicida miclobutanil após metabolismo in vitro por microssomas hepáticos de humanos. Ribeirão Preto: Biblioteca Digital de Teses e Dissertações da Universidade de São Paulo, 21 ago. 2018.

FONSECA, F. S. et al. Myclobutanil enantioselective risk assessment in humans through in vitro CYP450 reactions: Metabolism and inhibition studies. Food and Chemical Toxicology, v. 128, p. 202-211, 1 jun. 2019.

FREEMAN, S. et al. Children's diets, pesticide uptake, and implications for risk assessment: An Israeli case study. Food and Chemical Toxicology, v. 87, p. 88-96, 2016.

FUJII, N. D-amino acids in living higher organisms. Origins of Life and Evolution of the Biosphere, 2002.

FUSTINONI, S. et al. Biological monitoring of exposure to tebuconazole in winegrowers. Journal of Exposure Science \& Environmental Epidemiology, v. 24, n. 6, p. 643-649, 12 nov. 2014.

GODIN, S. J. et al. Identification of rat and human cytochrome P450 isoforms and a rat serum esterase that metabolize the pyrethroid insecticides deltamethrin and esfenvalerate. Drug 
Metabolism and Disposition, 2007.

HABENSCHUS, M. D. Estudos de inibição das enzimas do citocromo P450 pelo produto natural (-)-grandisina utilizando microssomas hepáticos de humanos. Ribeirão Preto: Biblioteca Digital de Teses e Dissertações da Universidade de São Paulo, 7 out. 2016.

HERNÁNDEZ, A. F.; GIL, F.; LACASAÑA, M. Toxicological interactions of pesticide mixtures: an updateArchives of Toxicology. Springer Verlag, , 1 out. 2017. Disponível em: <https://link.springer.com/article/10.1007/s00204-017-2043-5>. Acesso em: 18 mar. 2021

HERRERO-HERNÁNDEZ, E. et al. Occurrence of pesticides and some of their degradation products in waters in a Spanish wine region. Journal of Hydrology, v. 486, p. 234-245, 2013.

HODGSON, E. Future Considerations for Environmental and Human Health. In: A Textbook of Modern Toxicology. [s.l: s.n.].

HODGSON, E. Introduction to Pesticide Disposition. In: Hayes' Handbook of Pesticide Toxicology. [s.l: s.n.].

HODGSON, E. Introduction to Pesticide Biotransformation and Disposition. In: Pesticide Biotransformation and Disposition. [s.1: s.n.].

HU, Y.; KUPFER, D. Enantioselective metabolism of the endocrine disruptor pesticide methoxychlor by human cytochromes P450 (P450s): Major differences in selective enantiomer formation by various P450 isoforms. Drug Metabolism and Disposition, 2002.

JESCHKE, P. Current status of chirality in agrochemicals. Pest Management Science, 2018.

JÓNSDÓTTIR, S. Ó. et al. Physicologically Based Toxicokinetic Models of Tebuconazole and Application in Human Risk Assessment. Chemical Research in Toxicology, v. 29, n. 5, p. 715-734, 2016.

KIM, K. H.; KABIR, E.; JAHAN, S. A. Exposure to pesticides and the associated human health effects. Science of the Total Environment. Elsevier B.V., , 1 jan. 2017.

KRAMER, M. A.; TRACY, T. S. Enzyme Kinetics of Drug-Metabolizing Reactions and DrugDrug Interactions. In: Encyclopedia of Drug Metabolism and Interactions. Hoboken, NJ, USA: John Wiley \& Sons, Inc., 2012. p. 1-25.

LÄMMERHOFER, M. Chiral recognition by enantioselective liquid chromatography: Mechanisms and modern chiral stationary phases. Journal of Chromatography A, 2010.

LI, S. et al. Endocrine disrupting effects of tebuconazole on different life stages of zebrafish (Danio rerio). Environmental Pollution, 2019.

LI, Y. et al. Enantioselectivity in tebuconazole and myclobutanil non-target toxicity and degradation in soils. Chemosphere, 2015.

LIU, N. et al. Chiral bioaccumulation behavior of tebuconazole in the zebrafish (Danio rerio). Ecotoxicology and Environmental Safety, v. 126, p. 78-84, 2016. 
LV, X. et al. Effects of triazole fungicides on androgenic disruption and CYP3A4 enzyme activity. Environmental Pollution, v. 222, p. 504-512, 2017.

MA, F. et al. Gestational exposure to tebuconazole affects the development of rat fetal Leydig cells. Chemosphere, v. 262, p. 127792, 1 jan. 2021.

MA, Y.; GAN, J.; LIU, W. Chiral pesticides and environmental safety. ACS Symposium Series, v. 1085, p. 97-106, 13 dez. 2011.

MARTIGNONI, M.; GROOTHUIS, G. M. M.; DE KANTER, R. Species differences between mouse, rat, dog, monkey and human CYP-mediated drug metabolism, inhibition and induction. Expert Opinion on Drug Metabolism and Toxicology, 2006.

MCMURRY, J. Organic Chemistry, 8th Edition. Belmont, CA : Brooks Cole/Cengage Learning, 2012., 2012.

MERCADANTE, R. et al. Identification and Quantification of Metabolites of the Fungicide Tebuconazole in Human Urine. Chemical Research in Toxicology, v. 27, n. 11, p. 1943-1949, 17 nov. 2014.

NIROGI, R. et al. Chemical inhibitors of CYP450 enzymes in liver microsomes: Combining selectivity and unbound fractions to guide selection of appropriate concentration in phenotyping assays. Xenobiotica, v. 45, n. 2, p. 95-106, 2015.

NOUGADÈRE, A. et al. Dietary exposure to pesticide residues and associated health risks in infants and young children - Results of the French infant total diet study. Environment International, 2020.

OGILVIE, B. W.; USUKI, E.; YERINO, P. In Vitro Approaches for Studying the Inhibition of Drug-Metabolizing Enzymes and Identifying the Drug-Metabolizing Enzymes Responsible for the Metabolism of Drugs (Reaction Phenotyping) with Emphasis on Cytochrome P450. p. 249376,8 fev. 2008.

POPP, J.; PETŐ, K.; NAGY, J. Pesticide productivity and food security. A review. Agronomy for Sustainable Development, 2013.

POULSEN, R. et al. Tebuconazole disrupts steroidogenesis in Xenopus laevis. Aquatic Toxicology, 2015.

RING, B.; WRIGHTON, S. A.; MOHUTSKY, M. Reversible mechanisms of enzyme inhibition and resulting clinical significance. Methods in Molecular Biology, 2014.

ROSE, R. L. et al. Pesticide metabolism in humans, including polymorphisms. Scandinavian Journal of Work, Environment and Health, 2005.

ROSE, R. L.; HODGSON, E. Metabolism of Toxicants. In: A Textbook of Modern Toxicology. [s.l: s.n.].

ROSE, R. L.; HODGSON, E. Chemical and Physiological Influences on Xenobiotic Metabolism. In: A Textbook of Modern Toxicology. [s.l: s.n.]. 
RUDGE, C. V. C. et al. Levels of selected persistent organic pollutants in blood from delivering women in seven selected areas of São Paulo State, Brazil. Environment International, 2012.

SAITTA, M. et al. Gas chromatography-tandem mass spectrometry multi-residual analysis of contaminants in Italian honey samples. Food Additives \& Contaminants: Part A, p. 1-9, 20 fev. 2017.

SÁNCHEZ-GONZÁLEZ, S. et al. Pesticide residues in groundwaters and soils of agricultural areas in the Águeda River Basin from Spain and Portugal. International Journal of Environmental Analytical Chemistry, 2013.

SCHMIDT, F. et al. Combination effects of azole fungicides in male rats in a broad dose range. Toxicology, 2016.

SCOLLON, E. J. et al. In vitro metabolism of pyrethroid pesticides by rat and human hepatic microsomes and cytochrome P450 isoforms. Drug Metabolism and Disposition, 2009.

SEGEL, I. H. Enzyme Kinetics. In: Encyclopedia of Biological Chemistry: Second Edition. [s.l: s.n.].

SEIBERT, E.; TRACY, T. S. Fundamentals of enzyme kinetics. Methods in Molecular Biology, 2014a.

SEIBERT, E.; TRACY, T. S. Different enzyme kinetic models. In: Methods in molecular biology (Clifton, N.J.). [s.l: s.n.]. v. 1113p. 23-35.

SHEN, Z. et al. Stereoselective degradation of tebuconazole in rat liver microsomes. Chirality, v. 24, n. 1, p. 67-71, 2012.

SHUANG, Y. et al. Simultaneous enantiomeric determination of multiple triazole fungicides in fruits and vegetables by chiral liquid chromatography/tandem mass spectrometry on a bridged bis( $\beta$-cyclodextrin)-bonded chiral stationary phase. Food Chemistry, v. 345, p. 128842, 30 maio 2021.

SINZ, M. A. In Vitro and In Vivo Models of Drug Metabolism. In: Encyclopedia of Drug Metabolism and Interactions. Hoboken, NJ, USA: John Wiley \& Sons, Inc., 2012. p. 1-31.

STEHMANN, C.; DE WAARD, M. A. Relationship between chemical structure and biological activity of triazole fungicides against Botrytis cinerea. Pesticide Science, 1995.

STEPAN, A. F. et al. Metabolism-guided drug design. MedChemComm, 2013.

STEVENS, J.; WIENKERS, L. Cytochrome P450 Reaction Phenotyping. In: Drug Metabolizing Enzymes. [s.l: s.n.].

STRICKLAND, T. C.; POTTER, T. L.; JOO, H. Tebuconazole dissipation and metabolism in Tifton loamy sand during laboratory incubation. Pest Management Science, 2004.

TANG, J. et al. Metabolism of chlorpyrifos by human cytochrome p450 isoforms and human, 
mouse, and rat liver microsomes. Drug Metabolism and Disposition, 2001.

TANG, J. et al. In vitro metabolism of carbaryl by human cytochrome P450 and its inhibition by chlorpyrifos. Chemico-Biological Interactions, 2002.

TANG, J. et al. In vitro metabolism of fipronil by human and rat cytochrome P450 and its interactions with testosterone and diazepam. Chemico-Biological Interactions, 2004.

TSATSAKIS, A. M. et al. Determination of dialkyl phosphates in human hair for the biomonitoring of Exposure to organophosphate pesticides. Journal of Chromatography B: Analytical Technologies in the Biomedical and Life Sciences, 2010.

UN. Pesticide residues in food : 1994, report of the Joint Meeting of the FAO Panel of Experts on Pesticide Residues in Food and the Environment and the WHO Expert Group on Pesticide Residues, Rome, 19-28 September 1994. [s.1.] Rome : FAO, 1994.

UN. World population projected to reach 9.7 billion by 2050 | UN DESA | United Nations Department of Economic and Social Affairs. Disponível em: $<$ https://www.un.org/en/development/desa/news/population/2015-report.html $>$. Acesso em: 28 jun. 2020.

USEPA. US EPA-Pesticides; Tebuconazole | US EPA ARCHIVE DOCUMENT | Enhanced Reader.

USEPA. Basic Information about Pesticide Ingredients | Ingredients Used in Pesticide Products | US EPA. Disponível em: <https://www.epa.gov/ingredients-used-pesticideproducts/basic-information-about-pesticide-ingredients>. Acesso em: 7 jun. 2020.

VASCONCELOS, Y. Agrotóxicos na berlinda | Revista Pesquisa Fapesp. Disponível em: <https://revistapesquisa.fapesp.br/agrotoxicos-na-berlinda/>. Acesso em: 9 jun. 2020.

VOLAK, L. P.; GREENBLATT, D. J.; VON MOLTKE, L. L. In Vitro Approaches to Anticipating Clinical Drug Interactions. In: Drug-Drug Interactions in Pharmaceutical Development. Hoboken, NJ, USA: John Wiley \& Sons, Inc., 2007. p. 31-74.

WHITE, R. E. Review of Drug Metabolism in Drug Discovery and Development. In: Encyclopedia of Drug Metabolism and Interactions. Hoboken, NJ, USA: John Wiley \& Sons, Inc., 2012. p. 1-40.

WHO. WHO | PesticidesWho, 2018. Disponível em: <https://www.who.int/topics/pesticides/en/>. Acesso em: 7 jun. 2020.

YANG, J. DI et al. Effects of tebuconazole on cytochrome P450 enzymes, oxidative stress, and endocrine disruption in male rats. Environmental Toxicology, 2018.

ZHANG, H. et al. Cytochrome P450 reaction-phenotyping: An industrial perspective. Expert Opinion on Drug Metabolism and Toxicology, 2007.

ZHANG, Q. et al. Study on the stereoselective degradation of three triazole fungicides in sediment. Ecotoxicology and Environmental Safety, 2015. 
ZHAO, P. et al. Simultaneous enantioselective determination of 22 chiral pesticides in fruits and vegetables using chiral liquid chromatography coupled with tandem mass spectrometry. Food Chemistry, 2019.

ZHOU, J. et al. Triazole fungicide tebuconazole disrupts human placental trophoblast cell functions. Journal of Hazardous Materials, v. 308, p. 294-302, 2016.

ZHU, W. et al. Stereoselective degradation kinetics of tebuconazole in rabbits. Chirality, v. 19, n. 2, p. 141-147, 2007. 